\title{
Do diagnóstico à conservação da biodiversidade: 0 estado da arte do programa BIOTA/FAPESP
}

\author{
Jean Paul Metzger ${ }^{1}$ \& Lilian Casatti ${ }^{2}$ \\ Biota Neotropica v6 (n2)-http://www.biotaneotropica.org.br/v6n2/pt/abstract?point-of-view+bn00106022006 \\ Recebido em 20/12/05. \\ Versão reformulada recebida em 20/04/2006 \\ Publicado em 01/05/2006

\begin{abstract}
${ }^{1}$ Departamento de Ecologia, Instituto de Biociências (www.ib.usp.br), Universidade de São Paulo, Rua do Matão, 321, travessa 14, 05508-900 São Paulo, SP (jpm@ib.usp.br)

${ }^{2}$ Departamento de Zoologia e Botânica, IBILCE (www.ibilce.unesp.br), Universidade Estadual Paulista, Rua Cristóvão Colombo, 2265, 15054-000 São José do Rio Preto, SP (lcasatti@ibilce.unesp.br)
\end{abstract}

\begin{abstract}
Metzger, J.P and Casatti, L. From diagnosis to conservation: the state of the art of biodiversity conservation in the BIOTA/ FAPESP program. Biota Neotrop. Mai/Set 2006 vol. 6 no. 2, http://www.biotaneotropica.org.br/v6n2/pt/abstract?pointof-view+bn00106022006. ISSN 1676-0603

The main objective of this study was to analyze the contribution of the BIOTA/FAPESP program, one of the largest biodiversity programs in Brazil, in conservation issues, such as in the development of ecological indicators, definition of priority areas for conservation, and conservation viability analyzes. We found that the program was in its first phase (19992005) mainly focused on short-term punctual inventories at the community level, and in terrestrial and freshwater habitats. We identified some limitations in the use of the collected data for conservation purposes, and suggest possible measures to avoid those problems and bridge the gap between the biodiversity diagnosis and conservation: i) to adopt inventory protocols which would allow an easy comparison of data obtained in different geographical regions; ii) to stimulate multiple taxa inventories in areas with high conservation potential; iii) to encourage the integration of research with action, specially in the case of restoration projects; and iv) to link the BIOTA program with other applied programs (for example, the FAPESP Program of Public Policy) or programs that would allow the monitoring and understanding of functional aspects of the ecosystems (e.g., Long Term Ecological Research Program from CNPq).
\end{abstract}

Key words: BIOTA/FAPESP program, biological reserves, ecological indicators, priority areas, gap analysis, São Paulo state, Brazil

\section{Resumo}

Metzger, J.P and Casatti, L. Do diagnóstico à conservação da biodiversidade: o estado da arte do programa BIOTA/FAPESP. Biota Neotrop. Mai/Set 2006 vol. 6 no. 2, http://www.biotaneotropica.org.br/v6n2/pt/abstract?point-ofview+bn00106022006. ISSN 1676-0603

O principal objetivo deste estudo foi de avaliar a contribuição do Programa BIOTA/FAPESP, um dos maiores programas do Brasil voltados para o estudo da biodiversidade, em questões relacionadas com a conservação da biodiversidade, em particular no desenvolvimento de indicadores ecológicos, definição de áreas prioritárias e viabilização da conservação. Uma revisão da literatura nestes tópicos também é apresentada, visando uma melhor contextualização dos avanços e caminhos futuros a serem seguidos pelo programa BIOTA/FAPESP. Foi diagnosticado que este Programa encontra-se em uma fase de inventários pontuais, de curto prazo, essencialmente no nível de comunidade, e em ambientes terrestres e aquáticos continentais. Alguns problemas para o uso destes dados em conservação foram identificados e devem ser considerados para a definição de uma estratégia de conservação. São sugeridos possíveis caminhos futuros para a obtenção de dados mais direcionados para o uso para conservação da biodiversidade, em particular com: i) a adoção de protocolos de inventário visando facilitar a comparação de dados obtidos em diferentes locais; ii) a indução de levantamentos biológicos de diferentes taxa em áreas potenciais para a conservação; iii) o estímulo de projetos que aliem pesquisa e ação, em particular no caso de restauração ecológica; iv) a articulação do programa BIOTA com outros programas mais aplicados (por exemplo, o Programa de Políticas Públicas da FAPESP) ou que permitam o monitoramento e entendimento de aspectos funcionais dos sistemas ecológicos (Programa de Pesquisas Ecológicas de Longa Duração do CNPq).

Palavras-chave: programa BIOTA/FAPESP, unidades de conservação, indicadores ecológicos, áreas prioritárias, análise de lacunas, estado de São Paulo, Brasil 


\section{Introdução}

Diante da intensa degradação ambiental, contínua fragmentação de habitats, poluição da água, do ar e dos solos, introdução de espécies exóticas e conseqüente perda de diversidade biológica em todas as escalas, é nítida a crescente preocupação com a conservação de recursos naturais. Segundo definição adotada recentemente, a conservação da natureza é considerada como todo tipo de manejo da natureza, incluindo desde a proteção integral até a utilização sustentável e a restauração, visando a perpetuação das espécies e a manutenção da biodiversidade ${ }^{1}$ e dos recursos naturais de forma sustentável (Sistema Nacional de Unidades de Conservação, lei n. 9.985, 18 de julho de 2000).

A conservação da Natureza está sempre confrontada com duas questões-chave: onde a conservação é prioritária; e como viabilizar essa conservação em longo prazo. A resposta a estas questões necessita de definições claras dos alvos da conservação: trata-se de espécies, comunidades ou processos ecológicos, tais como os mecanismos de estabilização (auto-regulação) ou de adaptação (envolvidos na potencialidade evolutiva)? Ademais, devido à complexidade dos sistemas ecológicos, é necessário ainda estabelecer indicadores ecológicos, i.e. descritores eficientes do estado dos alvos de conservação.

O programa BIOTA, financiado pela Fundação de amparo à Pesquisa do Estado de São Paulo (FAPESP), é certamente uma das maiores iniciativas empreendidas no Brasil para o estudo e conservação da biodiversidade (http:/ /www.biota.org.br/). Em seus seis anos de existência (19992005), este programa já envolveu mais de 70 projetos e 500 pesquisadores. Dentre seus principais objetivos está avaliar a efetividade do esforço de conservação no Estado de São Paulo, identificando áreas e componentes prioritários para conservação (www.biota.org.br). Não há dúvidas de que o programa, através dos amplos levantamentos realizados no Estado de São Paulo e da sistematização de parte desta informação num banco de dados de amplo acesso, certamente estará contribuindo para a definição dos indicadores ecológicos e para a escolha de áreas prioritárias, dando subsídios para diretrizes de manejo.

Nosso objetivo foi mostrar o que o Programa BIOTA vem fazendo nestas três questões (indicadores, áreas prioritárias e viabilização da conservação), e sugerir possíveis caminhos futuros para uma aplicação mais direcionada dos dados do BIOTA em projetos de conservação. Uma revisão da literatura nestes tópicos permitirá uma melhor contextualização dos avanços e caminhos futuros a serem seguidos pelo programa BIOTA.

\section{Contextualização teórica \\ Indicadores Ecológicos}

Indicadores ecológicos podem ser definidos como parâmetros biológicos, baseados em populações, conjunto de populações ou propriedades sistêmicas, que, por suas características qualitativas e/ou quantitativas, retratam o estado de um sistema ecológico, permitindo detectar e monitorar eventuais mudanças nesse sistema ao longo do tempo (modificado de Blandin et al. 1986, Dale \& Beyeler 2001). O grande desafio é desenvolver indicadores que caracterizem efetivamente o estado de um determinado sistema ecológico e sejam simples o suficiente para serem medidos e interpretados sem dificuldade pelos tomadores de decisões (Dale \& Beyeler 2001).

Freqüentemente, o desenvolvimento de indicadores é baseado em um grande conjunto de descritores, que são dados qualitativos ou índices quantitativos, de qualquer origem, que descrevam aspectos bióticos, abióticos ou antrópicos do ambiente. Esses descritores variam em função do nível de organização biológica, e podem estar tanto baseados em padrões quanto em processos biológicos (Tabela 1). Para que estes descritores sejam considerados indicadores, há um novo avanço a ser dado através da pesquisa.

A pesquisa na área de indicadores ecológicos desenvolveu-se particularmente no caso de ambientes aquáticos continentais. Neste caso, o alvo da conservação é, em geral, a avaliação da integridade biológica (ou biótica) do sistema. Esta é definida como a capacidade de um ambiente manter e suportar uma biota comparável aos ambientes naturais de uma região (Karr \& Chu 1999), o que pressupõe a manutenção da capacidade de autorecuperação frente a distúrbios de origem antrópica, com o mínimo de interferência externa possível (Karr et al. 1986).

O primeiro trabalho a demonstrar que avaliações biológicas podem ser diretas e precisas e podem ser baseadas na ocorrência de táxons específicos (indicadores) foi o de Forbes \& Richardson (1919). As abordagens mais recentes de avaliação da integridade de ambientes aquáticos procuram combinar atributos (através de índices multimétricos) que representem a ampla diversidade ecológica existente e os diversos níveis de organização biológica. Um dos aspectos diferenciais dos índices bióticos mais recentes é que os parâmetros analisados sempre são comparados a uma condição de referência, definida como aquela que possui o mínimo de impacto de origem antrópica possível (Hughes 1995). Este é o caso do índice de integridade biótica ("index of biotic integrity”, IBI), proposto por Karr (1981), que foi baseado em características biológicas de comunidades de peixes de riachos. Este tem sido o paradigma de avaliação da integridade biológica de rios e riachos na América do

${ }^{1}$ Toda a diversidade de organismos que vivem num espaço, incluindo a diversidade genética, a complexidade ecológica do ambiente físico e a variedade das interações bióticas e de outros processos biológicos (definição baseada em Redford \& Richter 1999). 
Norte (e.g., Miller et al. 1988, Lyons et al. 1995, Roth et al. 1996, McCormick et al. 2001, Stewart et al. 2001) e já foi adaptado a várias regiões, tais como Europa (Oberdorff \& Hughes, 1992), Índia (Ganasan \& Hughes, 1998), África (Kamdem Toham \& Teugels, 1999) e América do Sul (Araújo et al. 2003, Bozzetti \& Schulz 2004), além de já ter sido estendido para ambientes marinhos (Jameson et al. 2001), estuarinos (Weisberg et al. 1997), lacustres (Karr \& Dionne 1991) e terrestres (Kimberling et al. 2001). O IBI tem se mostrado especialmente sensível quando utilizado em combinação com parâmetros físico-químicos para isolar possíveis causas de stress na biota aquática (Karr et al. 1985).

Algas (Hill et al. 2000), macroinvertebrados (Stribling et al. 1998), anfíbios (Micacchion 2002) e peixes (Karr 1981) figuram entre os organismos utilizados em avaliações de integridade biótica. Contudo, a maioria dos trabalhos publicados utiliza atributos tomados em comunidades de peixes, em razão da relativa facilidade de identificação taxonômica e maior disponibilidade de informações biológicas para este grupo. Além disso, as comunidades de peixes apresentam espécies representantes de vários níveis tróficos, influenciando a distribuição e abundância de outros organismos aquáticos (Karr 1981). No Brasil, o índice de integridade biótica com base em atributos de comunidades de peixes foi aplicado em alguns rios do Centro-Oeste (Ribeiro 1994), Sudeste (Araújo et al. 2003) e Sul (Bozzetti \& Schulz 2004), sendo ainda uma ferramenta pouco conhecida na avaliação da integridade biológica de sistemas aquáticos em nosso país.

Partindo da premissa de que espécies aquáticas têm exigências específicas quanto ao hábitat e que uma das mais sérias ameaças aos ambientes aquáticos tem sido a perda e degradação de hábitats, foi proposto o índice físico de hábitat ("Physical Habitat Index", PHI). Este índice, também multimétrico, inclui características de substrato, velocidade, profundidade, cobertura vegetal, condições da vegetação ripária e estabilidade das margens (Hall et al. 1999). O PHI, bem como suas variações (Barbour et al. 1999), tem sido especialmente útil para avaliar a condição dos parâmetros físicos que podem estar afetando as biotas aquáticas.

Em sistemas terrestres, o uso de índices de integridade é ainda pouco comum, possivelmente devido à maior dificuldade de se definir uma situação de referência pouco perturbada. O foco de interesse não é tanto a qualidade ou integridade do sistema (também mais difíceis de serem medidos em sistemas terrestres), mas sim o seu valor em termos de diversidade biológica. Nesse sentido, muitos indicadores ou representantes de biodiversidade terrestre têm sido propostos (Shafer 1999, Margules et al. 2002), considerando-se espécies (indicadores, guardachuva, chave, raras, endêmicas ou ameaçadas), grupos de espécies (e.g., grupos funcionais ou espécies com as mesmas sensibilidades às perturbações), comunidades (e.g., as de mais fácil identificação e levantamento no campo, como aves, árvores, e, em alguns casos, borboletas), tipos de ambientes (e.g., padrão de distribuição de cobertura vegetal natural), ecossistemas ou complexos de ambientes (ecoregiões), parâmetros abióticos (tipo de solo, relevo, formações geológicas, entre outros), qualidade do local (e.g., presença/abundância de espécies exóticas, degradação ou poluição) estrutura da paisagem (e.g., tamanho e grau de conectividade das áreas), ou numa combinação destes parâmetros. Estes representantes da biodiversidade, através de seus atributos (presença/ausência, abundância, riqueza, índices qualitativos, semi-quantitativos ou quantitativos), deveriam permitir acessar as variações no conjunto da complexidade biológica, apesar deste ponto ser altamente controverso (Wessels et el. 1999, Andelman \& Fagan 2000, Caro \& O’Doherty 1999, Araújo \& Humphries 2001, Lindenmayer et al. 2002). Certamente não há um único indicador ideal, e a qualidade ou pertinência destes descritores pode ser muito diferente, em particular em função da escala. Dados abióticos e de cobertura e uso do território, apesar de serem apenas indicadores indiretos da diversidade biológica, estão, atualmente, disponíveis para amplas regiões num formato digital, facilitando o uso nestas escalas. Por outro lado, dados biológicos estão em geral disponíveis em escalas mais regionais ou locais, restringindo a aplicação de modelos baseados na biota em escalas mais amplas, com notáveis exceções na Austrália (McKenzie et al. 1989, Pressey \& Nicholls 1989a, b), África do Sul (Freitag et al. 1996, Gaston \& Rodrigues 2003) e USA (Csuti et al. 1997). Bons resultados têm sido obtidos com a combinação destes indicadores, em particular na Papua Nova Guine, onde parâmetros ambientais foram usados junto com a distribuição de espécies raras ou ameaçadas (Margules \& Pressey 2000).

\section{Áreas Prioritárias}

Tradicionalmente, a escolha de áreas destinadas à conservação foi feita de forma oportunista, baseada em critérios de "virgindade” (ambientes naturais, "selvagens”, com uma idealizada ausência de interferência humana) e de beleza cênica. Este processo resultou, nos mais diversos países, numa distribuição tendenciosa de Unidades de Conservação (ou reservas) em áreas remotas, em geral com altitudes mais elevadas, relevos acidentados e solos pobres, áreas onde a exploração econômica do território era mais dificultada ou menos rendosa (Pressey et al. 1996, Scott et al. 2001). Este sistema ad hoc ou empírico de seleção de áreas para a conservação caracteriza-se por uma representatividade desigual dos diferentes ecossistemas/ ecoregiões ${ }^{2}$, sub-amostrando ambientes economicamente mais "produtivos", como áreas mais planas e de solos férteis

${ }^{2}$ Amplas áreas que apresentam similaridade na composição florística e faunística devido a limitações semelhantes em larga escala, condicionadas em particular por variáveis de clima, solos, tipos de rocha e de vegetação, em ambientes terrestres, e a variáveis físicoquímicas da água em ambientes aquáticos (Bailey 1998). Estas variáveis são consideradas como tendo uma forte influência na história evolucionária e na distribuição das espécies e comunidades.

http://www.biotaneotropica.org.br 
(Margules \& Pressey 2000). Ambientes nestas regiões são os mais ameaçados, e vêm sendo sistematicamente degradados, fragmentados ou simplesmente eliminados, apesar de serem ambientes de grande diversidade (Margules \& Pressey 2000, Scott et al. 2001). Para evitar esse viés, é necessário o estabelecimento de critérios mais objetivos para a escolha de áreas para conservação.

Foi apenas mais recentemente que a escolha de reservas passou a ser feita de forma a incorporar critérios biológicos, como a representatividade da ampla gama de atributos relacionados à biodiversidade, ou a manutenção da integridade biológica (Shafer 1999). Diante destes novos objetivos, e em função das limitações financeiras para a conservação, esse processo de escolha tem que ser otimizado.

Vários procedimentos sistematizados, baseados em conceitos de representatividade e persistência, têm sido propostos com esta finalidade (Shafer 1999, Soulé \& Terborgh 1999, Margules \& Pressey 2000, Gaston et al. 2001, Groves et al. 2002). Todas as espécies, comunidades e ecossistemas teriam que estar, idealmente, representadas nas reservas de uma maneira que haja garantia da persistência desta representatividade ao longo do tempo (Margules \& Pressey 2000, Gaston et al. 2001, 2002). Essa persistência dependerá do afastamento dos fatores de ameaça, e de características intrínsecas do sistema (e.g., extensão da reserva, tamanho da população, conservação dos processos ecológicos mantenedores ou geradores da diversidade). Esses procedimentos sistematizados para o planejamento da conservação incluem, em linhas gerais, as seguintes etapas: seleção de representantes/indicadores da biodiversidade; definição de metas ou objetivos para a conservação; avaliação das reservas existentes; seleção de novas áreas prioritárias; implementação, viabilização e manejo da rede de reservas.

A seleção de indicadores (surrogates for biodiversity) é uma etapa essencial, devido à impossibilidade de se considerar todos os aspectos da biodiversidade. Como foi discutido anteriormente, os melhores indicadores parecem ser aqueles que combinam características abióticas com características da distribuição de algumas espécies ou grupos biológicos.

Numa segunda etapa, é necessário definir mais precisamente quais são as metas da conservação, em função dos representantes da biodiversidade escolhidos. Qual é o tamanho mínimo e o padrão de distribuição que deve ter a espécie focal na rede de reservas? Em quantas unidades cada espécie deve aparecer? Qual o recobrimento mínimo de cada tipo de vegetação, ecoregião ou bioma nas unidades de conservação? Qual o grau mínimo de conectividade que a rede de reservas deve ter? Apesar destas metas serem quase sempre arbitrárias, sua definição é necessária para quantificar o sucesso da rede de reservas (em função das metas), comparar diferentes cenários, e avaliar qual a contribuição de cada reserva para o alcance das metas (Groves et al. 2002).
Antes de escolher novas áreas para conservação, é necessário avaliar a performance das reservas já existentes na realização das metas estabelecidas. Uma estratégia bem estabelecida nesse sentido foi desenvolvida nos EUA: o National Gap Analysis Program (GAP). Trata-se essencialmente de comparar a distribuição das espécies focais, ou de qualquer outro representante da biodiversidade, com a distribuição das reservas, de forma a apontar as lacunas (os gaps) da conservação (Jennings 2000).

A partir das definições anteriores, e do reconhecimento das lacunas, é possível estabelecer procedimentos objetivos para a seleção de novas reservas. Diversos procedimentos podem ser utilizados nesta etapa, como as análises multicriteriais (Stewart 1992), porém há uma técnica que vem recebendo muita atenção nesses últimos 15 anos: os algoritmos iterativos, que permitem, a partir de regras explícitas, selecionar, passo a passo, qual a melhor solução para um determinado problema (Pressey \& Nicholls 1989a, Pressey et al. 1993, Scott et al. 1993, Dobson et al. 1997, Ando et al. 1998, Howard et al. 1998, Margules \& Pressey 2000, Gaston \& Rodrigues 2003). Esses algoritmos estão baseados no princípio de complementaridade. Por exemplo, se o objetivo é representar pelo menos uma vez todas as espécies focais (representantes da biodiversidade) na rede de reservas, a seleção inicia o processo incluindo o sítio de maior riqueza de espécies focais. Num segundo passo, será selecionada a reserva que mais acrescentar espécies focais à primeira, ou seja, aquela que é mais complementar. A terceira reserva selecionada será a que melhor complementar as duas primeiras, e assim por diante, até atingir o objetivo de ter todas as espécies representadas pelo menos uma vez. As regras utilizadas pelos algoritmos são definidas pelo usuário e podem ser baseadas em diferentes características, como riqueza de espécies, raridade, presença ou abundância de espécies focais, ou numa combinação destas regras, de forma a não privilegiar apenas um aspecto da biodiversidade. Este procedimento deve permitir encontrar a solução mais eficiente para o problema levantado, ou seja, o tamanho mínimo de rede para atingir o objetivo da conservação.

No entanto, essa eficiência não garante a persistência desta condição ao longo do tempo. Para tanto, as medidas de representatividade têm que ser complementadas por medidas de persistência (Araújo \& Williams 2000), como, por exemplo, o tamanho mínimo viável de uma população. Devido à dificuldade de se obterem esses indicadores de persistência, outros caminhos podem ser utilizados: a múltipla representação das espécies focais (por exemplo, as espécies têm que estar presentes em 3 ou 5 reservas), de forma a haver uma redundância, reduzindo o risco de um único evento de perturbação levar uma espécie à extinção; representação dos sítios onde há picos de abundância das espécies, onde se supõe que a espécie seja mais estável (Gaston \& Rodrigues 2003); aumento da área 
de distribuição de cada espécie; incorporação de sítios de alta qualidade ou de áreas onde a espécie apresentou alta taxa de permanência no passado (Araújo et al. 2002); estabelecimento de critérios mínimos de arranjo espacial das reservas, em particular quanto ao grau de conectividade e tamanho das reservas (Gaston et al. 2002), de forma a aumentar as possibilidades de colonização a partir da vizinhança, e a diminuir os riscos de extinção local.

A qualidade da rede de reservas selecionadas pode ser medida sob diferentes critérios, em particular pela: i) eficiência (Pressey \& Nicholls 1989b), ou seja, a plena representatividade dos alvos/indicadores a um custo mínimo (em termos de número de reservas, área total das reservas, ou mesmo custo financeiro de desapropriação, se for o caso); ii) efetividade (Rodrigues et al. 1999), i.e. a porcentagem da biodiversidade representada na rede; iii) flexibilidade, ou seja a existência de várias combinações possíveis de reservas com eficiência similar, facilitando as negociações na hora da implantação das áreas de conservação; iv) e credibilidade, relacionada com a transparência das soluções e clareza dos meios empregados para chegar a elas (Rodrigues et al. 2000). É desta credibilidade que em muito dependerá o engajamento das pessoas para a viabilização das soluções propostas, logo para o sucesso da implementação da rede de reservas.

Apesar deste método ser mais eficiente na proteção da biodiversidade em relação à seleção ad hoc de reservas, a sua aplicação depende da existência, em todas as áreas a serem analisadas, de dados biológicos ou de seus indicadores, obtidos de forma padronizada. A ausência de informação adequada pode limitar substancialmente sua aplicação. Este pode ser, em particular, o caso em regiões tropicais onde a biodiversidade é elevada, e muitas vezes pouco conhecida.

\section{Viabilização da conservação}

A decisão de onde fazer conservação obviamente não responde à questão do como (Redford et al. 2003). As perguntas de onde e como são totalmente complementares. A implementação e viabilização das áreas escolhidas para conservação representam um dos maiores desafios da atualidade para os que se preocupam com a conservação. Não são raros os casos, no Brasil e no mundo, de Unidades de Conservação irreais, onde as terras não foram desapropriadas, onde não há zoneamento ou planejamento, ou seja, reservas que só existem "no papel”.
A implementação de uma reserva dependerá, inicialmente, de quem é o proprietário das terras (público ou privado) e de sua categoria (unidades de conservação de uso sustentável ou de proteção integral, conforme Sistema Nacional de Unidades de Conservação da Natureza, SNUC, Lei n. 9.985 de 18 de Julho de 2000). Em todos os casos, o plano de manejo da reserva é, sem dúvida, o principal instrumento legal para a viabilização da conservação. Um plano adequado tem de estar baseado em objetivos e alvos claramente definidos, num conhecimento aprofundado da reserva, que dará embasamento para o seu zoneamento, e num efetivo envolvimento da população do seu interior ou do seu entorno, sem o qual poucas ações de conservação conseguem ter respaldo e sucesso. O monitoramento das ações de conservação, que pode ser feito de forma experimental, é sem dúvida um passo fundamental para avaliar a efetividade de um plano de manejo (Margules \& Pressey 2000).

Ademais, devido ao viés na representatividade das unidades de conservação, fica cada vez mais clara a necessidade de se conservarem fragmentos de habitat natural em áreas já intensamente modificadas pelo Homem, onde se encontram os melhores solos para a agricultura ou outra atividade humana. Esses são os sistemas mais perturbados e menos representados nas redes de reservas (Margules \& Pressey 2000). No Brasil, a conservação em propriedades particulares está basicamente regida pelo Código Florestal (Lei 4.771, de 15 de setembro de 1965), que estabelece as Áreas de Preservação Permanente e as Reservas Legais ${ }^{3}$. Mais recentemente, foram criadas categorias de reservas que regulam o uso de recursos em áreas particulares, como as Áreas de Proteção Ambiental, Áreas de Relevante Interesse Ecológico, Reservas da Biosfera e Reservas Particulares do Patrimônio Natural, as RPPNs (Brasil 2000). Em todos estes casos, a dicotomia homem-natureza, fortemente impregnada na filosofia da conservação brasileira (que por sua vez foi influenciada pela Norte Americana, Diegues 1996), deixa de existir de forma tão rígida, dando maior espaço para o envolvimento dos diferentes atores da conservação. Este parece ser um passo fundamental para a efetivação das iniciativas de conservação.

Porém, está cada vez mais claro que não se pode pensar na gestão de reservas como se fossem ilhas de biodiversidade (Wiens 1995, Peck 1998, Shafer 2001, Haila 2002, entre outros). Toda reserva, isoladamente, estará

${ }^{3}$ Áreas de preservação permanente são, basicamente, aquelas em que a vegetação nativa é essencial para conter processos de erosão e proteger rios e mananciais, como ao longo de cursos ou corpos d'água (artificiais ou naturais), junto a nascentes, no topo dos morros, nas montanhas e serras (em altitudes acima de 1.800 metros), nas encostas com declividade acima de 45 graus, em bordas de tabuleiros e chapadas e nas restingas. A reserva legal é uma percentagem da área útil da propriedade que deve permanecer com a vegetação nativa. De acordo com o Conselho Nacional de Meio Ambiente, essa reserva é "necessária ao uso sustentável dos recursos naturais, à conservação e reabilitação dos processos ecológicos, à conservação da biodiversidade e ao abrigo e proteção de fauna e flora nativas”. 
fadada à perda progressiva de sua diversidade, à degradação do seu entorno, à invasão de espécies exóticas ou à propagação de outras perturbações. Todo plano de manejo deve considerar a inserção da reserva dentro da sua zona tampão, e a manutenção das possibilidades de fluxos biológicos entre reservas vizinhas. A gestão de Unidades de Conservação vem progressivamente passando de uma gestão de ilhas para uma gestão de redes de unidades, baseado em particular na teoria de metapopulações (Levins 1970, Hanski \& Gilpin 1997, Hanski 1999), e mais recentemente em princípios de ecologia de paisagens (Forman 1995, Metzger 2001, Gutzwiller 2002). Esta evolução fica clara quando se analisam os princípios de gestão de mosaicos de Unidades de Conservação, propostos no novo Sistema Nacional de Unidades de Conservação (SNUC, Decreto n. 4.940 de 22 de Agosto de 2002), ou então nos conceitos de "corredores ecológicos” (CI \& IESB 2000) ou de planejamento ecoregional (Groves et al. 2000, 2002).

A integração de áreas de conservação de sistemas terrestres e aquáticos deve ficar claramente definida neste planejamento ecoregional. É consenso que a integridade da biota aquática responde às atividades humanas que afetam o uso e cobertura da terra ao longo da bacia de drenagem (Roth et al. 1996), porém principalmente na área de entorno. Esta, por sua vez, atua como tampão final para as atividades exercidas no restante da bacia e regula parte do ciclo hidrológico. O esforço para conservação de águas continentais superficiais deve também ser direcionado para as cabeceiras (Saunders et al. 2002), pois a biota de cabeceiras e de pequenos riachos é mais vulnerável às perturbações causadas por múltiplos usos da terra (Gregory et al. 1991). Além disso, as cabeceiras também desempenham papel importante na proteção de trechos inferiores de cursos d’água (Dale Jones et al. 1999). Por exemplo, em alguns riachos da bacia do Rio Tennessee, nos EUA, Dale Jones et al. (1999) verificaram que uma das mais importantes variáveis que respondeu pelas diferenças encontradas entre as comunidades de peixes foi a extensão de trechos sem vegetação ripária, que mostrou correlação negativa com a abundância de peixes.

Com a disponibilidade de sistemas de informação georreferenciada (SIG) é possível organizar unidades hidrológicas dentro de paisagens ecologicamente relevantes, desenvolvendo um sistema combinado de análise de atributos geológicos, morfológicos, físicoquímicos e biológicos (Bauer \& Ralph 2001). Um bom exemplo da integração entre diferentes níveis de organização biológica, escalas e ferramentas de análise é o trabalho realizado por Roth et al. (1996). Nesse trabalho, foi feita uma avaliação da integridade dos riachos de uma região agrícola nos Estados Unidos através do emprego do IBI e do HI ("habitat index”, uma variante do índice físico do hábitat). Tais medidas foram comparadas com as condições locais ripárias e em nível de paisagem, em diferentes escalas espaciais. A qualidade biótica e do hábitat foram negativamente correlacionadas com a extensão de áreas cultivadas e positivamente correlacionadas com a extensão de áreas florestadas. As correlações mais fortes foram obtidas no nível de drenagem, indicando que o uso da terra é o principal fator determinante da integridade dos riachos analisados.

\section{Qual a contribuição atual do BIOTA para a conservação?}

O diagnóstico da contribuição do programa BIOTA/ FAPESP para a conservação foi feito considerando todos os projetos em andamento (45) ou finalizados (25) até dezembro de 2005, num total de 70 projetos (http:// www.biota.org.br/projeto/index?searc; anexo 1). Estes foram analisados em termos do principal nível de organização considerado (Figura 1), de seu objetivo principal (Figura 2) e de sua contribuição para a conservação (Figura 3). Para esta última tipologia, foram incluídas categorias que envolviam ações diretas de conservação (e.g., restauração, pesquisa-ação), até os projetos que tinham a conservação apenas como objetivo indireto, contribuindo pelo fornecimento de dados e futuro subsídio para a tomada de decisão. Procurou-se também incluir contribuições em diferentes níveis de organização, do molecular/genético (e.g., bioprospecção) ao ecossistêmico/paisagístico (definição de áreas prioritárias para conservação), assim como projetos estritamente biológicos e aqueles que incluíam as dimensões humanas na sua análise (projetos de viabilização da conservação, de desenvolvimento sustentável), e enfim aqueles mais metodológicos.

Independente dos ambientes considerados (40 projetos em Mata Atlântica; 18 em Cerrado, 14 de águas continentais e 6 de regiões costeiras ou marinhas, lembrando que alguns projetos trabalham em mais de um ambiente), há claramente um predomínio de projetos que enfatizam análises no nível de comunidades ou ecossistemas (apesar de muito destes estudos considerarem também aspectos populacionais) e que estão essencialmente realizando inventários (salvo no caso do Cerrado, onde há vários estudos de bioprospecção). No geral, a principal contribuição destes projetos para conservação é indireta, através do fornecimento de informações (43 projetos, i.e. 60\%) ou através da identificação de possíveis fatores de degradação (12 projetos). Há ainda um número considerável de projetos (19) envolvidos com a valoração econômica da biodiversidade, em geral através de estudos de bioprospecção. Por outro lado, nenhum projeto foi incluído nas categorias de conservação ex-situ, restauração, desenvolvimento sustentável, pesquisa-ação, e apenas um projeto lida com a viabilização da conservação. É clara a lacuna com questões mais aplicadas. Somente recentemente foram apresentados cinco projetos com diferentes abordagens sobre aspectos culturais e sociais da biodiversidade. 


\section{Indicadores ecológicos}

Em ambientes terrestres, apenas quatro projetos, todos na Mata Atlântica, estão abordando questões relacionadas com o estabelecimento de indicadores ambientais. Porém, o único projeto do Programa BIOTA que tem como principal objetivo a definição de espécies ou grupos indicadores é o projeto de Lepidoptera (coordenado pelo Dr. Keith S. Brown Jr.; anexo 1). Neste caso, estão sendo feitos estudos com espécies que se alimentam de frutas, o que inclui borboletas de três sub-famílias de Nymphalidae (Ithomiinae, Satyrinae e Biblidini) e uma de Lycaenidae (Riodininae). Essas espécies são consideradas como boas indicadoras de perturbação (Brown e Freitas 2000). Os levantamentos, feitos em diferentes locais do estado de São Paulo com o mesmo protocolo de levantamento, devem não apenas permitir o teste de sensibilidade à fragmentação, mas também o uso das listagens em programas de seleção de áreas prioritárias para conservação. Um outro projeto voltado para o estabelecimento de indicadores biológicos é o de viabilidade de conservação dos remanescentes de Cerrado (Dra. Marisa Bitencourt; anexo 1). Num trabalho resultante deste projeto, foram propostos 15 indicadores para comparar o valor para conservação de 86 áreas de cerrado do estado de São Paulo (Durigan et al. 2006). Estes indicadores incluem aspectos biológicos (riqueza, ocorrência de espécies raras e endêmicas, representatividade fitogeográfica, proteção de mananciais, diversidade de fisionomias), espaciais (tamanho, conectividade e quantidade de borda do fragmento, além do tipo de matriz no entorno) e de grau de integridade/perturbação (presença de espécies invasoras, ocorrência de fogo, gado, lixo e corte seletivo). Dois outros projetos, que estão agregando grande quantidade de informação para uma mesma área geográfica, terão também como produto esperado a definição de indicadores de conservação (projeto coordenado pelo Dr. Ricardo Rodrigues) ou de biodiversidade (coordenado pelo Dr. Jean Paul Metzger).

Dos 18 projetos que abordam estritamente ambientes aquáticos (nove em águas continentais superficiais, sete em ambientes marinhos, um em estuário e um em ambientes marinhos e dulciaqüícolas), a maioria (13) tem como objetivo principal realizar inventários que poderão futuramente subsidiar políticas de conservação. Destes, apenas três têm adicionalmente se preocupado em utilizar seus grupos biológicos para buscar indicadores de interferência antrópica no sistema (dois projetos sobre crustáceos, insetos, oligoquetos e moluscos, coordenados pelo Dr. Cláudio Froehlich e zooplâncton, coordenado pela Dra. Takako M. Tundisi; anexo 1). Apenas um projeto propõe gerar indicadores e avaliar a integridade biológica de uma área (utilizando o IBI), e este somente se tornou executável em razão da fauna da região em questão ser razoavelmente conhecida.

\section{Áreas prioritárias}

Poucos projetos incluem, entre seus objetivos principais, a definição de áreas prioritárias para conservação. Dentre as exceções, estão, numa escala mais regional, englobando todo ou parte do estado de São Paulo, os projetos de conservação de remanescentes de Cerrado (Dra. Marisa Bitencourt) e de estudo de Lepidoptera (Dr. Keith Brown Jr), e numa escala mais local (100 km²), o projeto de fragmentação de Mata Atlântica (Dr. Jean Paul Metzger). Ademais, outros projetos, que trabalham com a distribuição potencial das espécies (Dr. Vanderlei Peres Canhos) ou com a definição de regiões de endemismo (Dr. Mário de Vivo, Dr. Dalton Amorim; anexo 1) poderiam contribuir para a definição de áreas prioritárias para a conservação.

Nos ambientes aquáticos, apenas os projetos de crustáceos, insetos, oligoquetos e moluscos de água doce (Dr. Cláudio Froehlich) e zooplâncton (Dra. Takako M. Tundisi) se propõem diretamente a identificar áreas prioritárias para conservação. Porém, o projeto com peixes coordenado pela Dra. Lilian Casatti, que visa caracterizar e avaliar a integridade biótica de riachos do noroeste do estado de São Paulo, pode também, ao definir as áreas de maior integridade, indicar sítios prioritários para conservação ou restauração.

Vários projetos teriam potencial para serem utilizados em procedimentos sistematizados, a partir de algoritmos iterativos, de seleção de áreas prioritárias, caso eles inventariassem diversas regiões do estado com o mesmo protocolo de coleta.

\section{Viabilização da conservação}

Apenas um projeto lida com esta questão, no caso, o projeto de Viabilidade de Conservação dos remanescentes de Cerrado do Estado de São Paulo, coordenado pela Dra. Marisa Bitencourt (Bitencourt \& Mendonça 2004). Este projeto aliou um diagnóstico biológico de áreas previamente indicadas como prioritárias para conservação, com um diagnóstico do perfil dos proprietários no entorno dos fragmentos, de modo a descobrir a predisposição destes para se tornarem parceiros em ações de conservação, e com uma avaliação do potencial mercadológico das espécies lenhosas de cerrado encontradas e de outras com valor econômico conhecido. Ademais, foi ainda implantado um projeto de desenvolvimento sustentado com famílias assentadas numa área com remanescentes de cerrado. Esta é, por enquanto, a única iniciativa dentro do programa BIOTA que combina análises biológicas e sócio-econômicas na busca de parâmetros de sustentabilidade ecológica, aliada a conceitos de justiça social e desenvolvimento econômico.

No geral, poucos projetos estão preocupados com o estabelecimento de indicadores ambientais, com a definição de áreas prioritárias para conservação, ou com outros aspectos práticos da efetivação da conservação, sendo que 
a maioria procura essencialmente fornecer subsídios futuros para a conservação. O Programa pode ser considerado, no seu conjunto, como estando numa fase de diagnóstico, onde se procura descrever a biodiversidade e sua variação espacial e temporal, com o uso dos mais variados descritores.

\section{Unindo pesquisa e conservação: sugestões de caminhos futuros \\ Indicadores ecológicos}

Não há dúvida de que o Programa BIOTA tem muito a contribuir na definição dos representantes ou indicadores da biodiversidade, diante do enorme esforço amostral que vem sendo feito, e da sistematização deste conhecimento num único banco de dados georeferenciado. A partir dos dados coletados, considerados aqui como descritores da biodiversidade, será possível testar que espécies, grupos de espécies, variáveis abióticas, parâmetros da estrutura de paisagem, ou que combinação destes parâmetros melhor retrata as variações da diversidade observada para diferentes grupos taxonômicos.

A fase de diagnóstico/inventário, no qual se encontra o programa como um todo, é inquestionavelmente subsidiária a qualquer trabalho futuro que envolva a proposição de indicadores para conservação. Para que estes inventários e os seus atuais descritores possam gerar bons indicadores do estado de conservação, seria necessário:

-Padronizar o esforço amostral. Nem todos os 43 projetos do Programa BIOTA cujo objetivo principal é realizar inventários demonstram uma preocupação com a padronização amostral, apesar desta ser essencial para a comparação das diferentes áreas de amostragem;

-Enfatizar a busca por indicadores de integridade biológica, numa estratégia traçada em conjunto com especialistas nos diversos grupos de organismos, de forma a representar o conjunto da diversidade ecológica;

- Considerar a adequação dos indicadores à escala espacial e temporal e ao nível de organização biológica (Tabela 1). Indicadores de padrões ou processos de curto prazo não podem ser aplicados para escalas espaciais e temporais globais e de longo prazo, ou vice-versa;

· Considerar diferentes ameaças à conservação, tais como a fragmentação, a poluição, a caça ou a exploração predatória de recursos naturais, de forma a testar a sensibilidade dos indicadores às causas das perturbações;

-Trabalhar com gradientes de degradação, ou seja, não apenas em áreas bem preservadas, mas também em áreas degradadas, para que seja possível calibrar os indicadores. Quando possível e pertinente, principalmente em ambientes aquáticos, deve-se procurar estabelecer comparações com sítios de referência, que poderiam ser áreas em estado mais avançado de sucessão (dentro de quadro teórico da teoria climácica), ou áreas equivalentes à estudada, porém sem alteração originada pelo homem (no quadro de teorias de estratégias adaptativas, Blandin et al.1986);

-Analisar a influência de eventos biogeográficos e processos filogenéticos históricos na geração de elevado grau de endemismo e/ou de diversidade em determinadas regiões. Esses processos são essenciais para se entenderem os atuais padrões de biodiversidade (Crandall et al. 2000);

·Executar o monitoramento ao longo do tempo, através de pesquisa de longo prazo, permitindo assim identificar mudanças em processos ecológicos e, conseqüentemente, desenvolver possíveis indicadores baseados em aspectos funcionais dos sistemas (Figura 4).

Acreditamos que o trabalho de análise de descritores, seleção de indicadores e sua aplicação em programas de monitoramento são atividades destinadas ao campo da pesquisa, enquanto que a execução dos protocolos de monitoramento restringe-se ao campo técnico. Evidentemente, é desejável que exista um momento de interface entre os dois campos, visando assegurar a devida compreensão do papel de tais indicadores no processo de monitoramento (Figura 4).

Finalmente, para que um dos frutos do Programa BIOTA seja a obtenção de bons indicadores de estado de conservação, válidos para diferentes grupos taxonômicos e condições ecológicas (e.g., tipos de paisagem, vegetação e parâmetros abióticos), é imperativa a integração espacial das informações e descritores gerados pelos diferentes projetos.

\section{Como os dados do BIOTA podem auxiliar para a implementação de um procedimento sistematizado de conservação?}

A aquisição de informações sobre a ocorrência da biota numa ampla área geográfica (e.g., estado de São Paulo), para os mais diversos taxa, nas mais diversas escalas e níveis de organização biológica, e a compilação desta informação num banco de dados georeferenciado, acessível para toda a comunidade científica, é sem dúvida um passo considerável para se definirem prioridades de conservação.

A maior contribuição do BIOTA, em termos de priorização de áreas para a conservação é, sem dúvida, esta ampla disponibilização da informação biológica. Essa base de dados potencializa o uso de algoritmos iterativos de seleção baseados não apenas em dados do ambiente abiótico, mas também na ocorrência de espécies ou grupos de espécies, permitindo comparar regiões quanto aos seus valores em termos de complementaridade, em relação às unidades de conservação já existentes.

A maior limitação está na aquisição de dados com diferentes metodologias, esforços amostrais e de forma irregular no espaço (super-amostrando os sítios de maior potencial para se encontrar as espécies estudadas). Até o 
momento, os dados inseridos no SinBiota ainda não refletem o real estado de conhecimento dos pesquisadores, e desta forma ainda não podem ser utilizados para a identificação de áreas prioritárias para a conservação, seja devido à existência de lacunas espaciais de informações, seja pela dificuldade de se compararem os dados obtidos com métodos e/ou esforços distintos. Apesar desta limitação não ser plenamente "remediada" a posteriori, o uso de modelos de previsão potencial de ocorrência (como o GARP, Genetic Algortihm of Rule-set Production) pode amenizar esforços amostrais desiguais ou irregularmente distribuídos no espaço. O ideal é, sem dúvida, a coleta sistematizada de informação no campo, relatando não apenas a presença mas também a ausência das espécies.

Para que o programa BIOTA possa contribuir de forma mais efetiva no estabelecimento de estratégias de seleção sistematizada de áreas para a conservação, seria necessário:

- A coleta de informação de forma sistematizada (mesmo esforço amostral e metodologia em cada local) para cada grupo de espécies considerado, de forma que esses dados sejam espacialmente comparáveis. Modelos de seleção de reservas podem funcionar adequadamente com informação obtida com pouco esforço amostral, mas não são confiáveis se o esforço é desigual (Gaston \& Rodrigues 2003). Essa preocupação com a padronização dos levantamentos, observada em alguns projetos, como no caso de Arachnida e Myriapoda, Isoptera e Hymenoptera, Lepidoptera, peixes de riachos e no projeto de viabilidade de conservação de áreas de cerrado, é, assim, essencial.

- O estabelecimento de uma grade de pontos (como feito na África do Sul, Gaston \& Rodrigues 2003) ou de áreas de relevante interesse (fragmentos remanescentes, por exemplo), onde seriam coletados dados de diferentes grupos taxonômicos (de preferência, incluindo grupos de vertebrados, invertebrados e plantas).

- O registro sistematizado das ausências das espécies na grade de pontos. É apenas com este registro que se terá certeza que a ausência da espécie no banco de dados não é devida à ausência ou insuficiência da amostragem no campo, informação crucial para todo modelo de seleção de reservas.

- Avaliação das unidades de conservação já existentes, de forma a realizar a seleção de novas áreas utilizando-se o princípio da complementaridade.

\section{Como o BIOTA pode auxiliar na viabilização da conservação?}

Duas alternativas complementares aparecem na discussão sobre a viabilização da conservação: i) a criação de mecanismos para a conservação em propriedades privadas; ii) o auxílio à gestão das Unidades de Conservação já existentes.
O estímulo à conservação de áreas inseridas em propriedades particulares é visto, pelos integrantes do programa BIOTA, como algo factível e de alta prioridade, estando dentro da alçada do programa e sendo objeto de pesquisa de um dos seus projetos. Neste aspecto, os dados gerados pelo programa BIOTA deveriam ser úteis na valoração dos recursos encontrados em manchas remanescentes de vegetação natural, no embasamento de programas de bioprospecção e uso sustentável destes recursos, na criação de Reservas Particulares do Patrimônio Natural (RPPN) ou ainda na obtenção de créditos por ações de restauração de áreas naturais (p.ex., através dos Mecanismos de Desenvolvimento Limpo). A parceria do Programa BIOTA com o Programa de Políticas Públicas da FAPESP poderia ainda viabilizar formas participativas de conservação, aliando ONGs, prefeituras e órgãos ambientais.

Ademais, os resultados até então obtidos pelo Programa BIOTA poderiam atuar como auxiliares na gestão das atuais Unidades de Conservação, como é o caso dos trabalhos realizados por Casatti et al. (2001) e Stopiglia (2001) com a ictiofauna do Parque Estadual Morro do Diabo e de seu entorno, que geraram informações subsidiárias à execução do Plano de Manejo do Parque. Contudo, cabe aqui ressaltar que muitas vezes a pesquisa realizada em Unidades de Conservação é divulgada de forma estritamente acadêmica, o que distancia a pesquisa da gestão. Além disso, geralmente os projetos são restritos às áreas mais atrativas e preservadas das Unidades, não servindo para a resolução dos problemas mais urgentes. Talvez fosse o momento de se pensar em fazer pesquisa de forma mais pragmática, utilizando os problemas das Unidades como uma oportunidade para se realizarem projetos experimentais.

Finalmente, deve-se ainda ressaltar a importância de ações no nível de bacias hidrográficas, de forma a integrar os conhecimentos obtidos em ambientes aquáticos e terrestres. Iniciativas de integração, como as promovidas pelo projeto do Dr. Luiz Martinelli (anexo 1), devem ser estimuladas.

É desejável, também, o envolvimento com projetos em andamento fora do Programa BIOTA, a exemplo da iniciativa tomada pelo Ministério Público de Monte Aprazível que, com a participação da comunidade, busca recuperar a vegetação ripária da micro-bacia do Córrego Água Limpa no município de Monte Aprazível. A equipe do Laboratório de Ictiologia de São José do Rio Preto, UNESP, terá o papel de acompanhar a integridade biótica das comunidades de peixes desse córrego em um estudo de longo prazo.

Em síntese, os dados obtidos pelos projetos do BIOTA devem ser utilizados para a efetiva ação na viabilização da conservação, seja auxiliando na gestão das Unidades de Conservação já existentes, ou mesmo na criação de mecanismos de conservação em áreas privadas. Outros benefícios indiretos deverão ainda ser obtidos, como o embasamento para o zoneamento ecológico-econômico do 
estado, ou ainda a atualização da lista de espécies ameaçadas. Em todos esses casos, recomenda-se também uma abordagem experimental.

\section{Considerações Finais}

Apesar do Programa BIOTA estar em uma fase de inventários pontuais, de curto prazo, essencialmente no nível de comunidade, alguns problemas foram identificados e devem ser analisados para que um plano de ação em termos de conservação possa ser traçado dentro do Programa:

• Os inventários não são sempre comparáveis; mesmo dentro de um mesmo projeto ou grupo taxonômico, o esforço amostral não é sempre padronizado;

•Existem muitas áreas geográficas não representadas, o que implica na distribuição desigual de levantamentos;

·Poucos níveis de organização estão representados, muitas vezes restritos a comunidades.

Em adição, apesar de existirem projetos aplicados que procuram viabilizar a conservação, ainda existem poucos projetos com ações aplicadas (Figura 3), tanto no campo da pesquisa-ação, quanto no manejo (diagnóstico) experimental e na restauração. Também os aspectos sócio-econômicos foram pouco privilegiados nesta primeira fase do Programa BIOTA, apesar de sua importância no processo de viabilização da conservação. A sociedade, sobretudo as comunidades locais que serão afetadas pelas restrições de uso dos recursos naturais, deve participar do processo de criação, implantação e gestão das unidades de conservação, públicas ou privadas.

Assim, as conclusões e propostas podem ser visualizadas no fluxograma da Figura 5 e se resumem a:

-Adotar protocolos de inventário visando a obtenção de dados comparáveis em termos de esforço amostral;

-Incentivar (junto aos coordenadores de projetos) a proposição de indicadores a serem testados a partir dos descritores;

-Incentivar a integração espacial e a convergência temática em projetos já existentes (tanto vinculados ao programa BIOTA quanto aqueles não vinculados, desde que sejam de interesse para o programa), através de pesquisa induzida em áreas prioritárias para conservação e da maior integração entre os bancos de dados de diferentes projetos;

-Incentivar projetos que aliem pesquisa e ação, em particular projetos de restauração e diagnóstico experimental;

- Articular a aproximação do Programa BIOTA ao Programa de Políticas Públicas com a finalidade de estimular e viabilizar ações de conservação.

Finalmente, uma nova fase do Programa BIOTA poderia ser articulada de forma a estimular projetos de longo prazo, que permitiriam o monitoramento e entendimento de aspectos funcionais dos sistemas ecológicos. Este programa, batizado aqui de "BIOTA Funcional”, poderia ser feito em parceria com outros programas similares já existentes, como o Programa de Pesquisas Ecológicas de Longa Duração (PELD-CNPq).

\section{Agradecimentos}

O diagnóstico e as recomendações deste texto estão baseados nas discussões e conclusões sobre "Indicadores de conservação \& avaliação do conhecimento para conservação”, ocorridas durante o I Workshop de Síntese do Programa BIOTA/FAPESP, no período de 24 a 26 de novembro de 2002, na Universidade Federal de São Carlos. Nós gostaríamos da agradecer a contribuição de todos os membros deste grupo de discussão, em especial ao Prof. Luciano M. Verdade, do Laboratório de Ecologia AnimalESALQ-USP, nosso provocador, por sua valiosa contribuição na gênese das idéias, e por sua revisão crítica de uma versão preliminar deste capítulo. Agradecemos ainda a Dra. Giselda Durigan e o Dr. Carlos Joly por comentários em versão prévia deste manuscrito.

\section{Referências bibliográficas}

ANDELMAN, S.J. \& FAGAN, W.F. 2000. Umbrellas and flagships: efficient conservation surrogates or expensive mistakes? PNAS 97:5954-9.

ANDO, A., CAMM, J., POLASKY, S. \& SOLOW, A. 1998. Species distributions, land values, and efficient conservation. Science 279:2126-8.

ARAÚJO, F.G., FICHBERG, I., PINTO, B.C.T. \& PEIXOTO, M.G. 2003. A preliminary index of biotic integrity for monitoring the condition of the Rio Paraíba do Sul, southeast Brasil. Envir. Manag. 32:516-26.

ARAUJO, M.B. \& WILLIAMS, P.H. 2000. Selecting areas for species persistence using occurrence data. Biol. Cons. 96:331-45.

ARAUJO, M.B., HUMPHRIES, C.J., DENSHAM, P.J., LAMPINEN, R., HAGEMEIJER, W.J.M., MITCHELLJONES, A.J. \& GASC, J.P. 2001. Would environmental diversity be a good surrogate for species diversity? Ecography 24:103-10.

ARAUJO, M.B., WILLIAMS, P.H. \& FULLER, R.J. 2002. Dynamics of extinction and the selection of nature reserves. P. Roy. Soc. B 269:1971-80.

BAILEY, R.G. 1998. Ecoregions: the ecosystem geography of the oceans and continents. Springer-Verlag New York.

BARBOUR, M.T., GERRITSEN, J., SNYDER, B.D. \& STRIBLING, J.B. 1999. Rapid bioassessment protocols for use in streams and wadeable rivers: periphyton, benthic macroinvertebrates and fish. Second edition. EPA 841-B-99-002. U. S. Environmental Protection Agency; Office of Water, Washington, D.C. 
BAUER, S.B. \& RALPH, S.C. 2001. Strengthening the use of aquatic habitat indicators in Clean Water Act Programs. Fisheries 26:14-24.

BITENCOURT, M.D. \& MENDONÇA, R.R. 2004. Viabilidade de conservação dos remanescentes de cerrado no Estado de São Paulo. Annablume e Fapesp, São Paulo.

BLANDIN, P., MOLLON, A. \& NATAF, L. 1986. Bioindicateurs et diagnostic des systèmes écologiques. Bull. Ecol. 17:215-307.

BOZZETTI, M. \& SCHULZ, U. H. 2004. An index of biotic integrity based on fish assemblages for subtropical streams in southern Brazil. Hydrobiol. 529:133-44.

BRASIL, 2000. Lei 9.985, de 18 de julho de 2000. Instituiu o Sistema Nacional de Unidades de Conservaçãoda Natureza, Brasília.

BROWN, K.S. \& FREITAS, A.V.L. 2000. Atlantic forest butterflies: Indicators for landscape conservation. Biotropica 32:934-56.

CARO, T.M. \& O’DOHERTY, G. 1999. On the use of surrogate species in conservation biology. Cons. Biol. 13:805-14.

CASATTI, L., LANGEANI, F. \& CASTRO, R.M.C. 2001. Peixes de riacho do Parque Estadual Morro do Diabo, bacia do Alto rio Paraná, SP. Biota Neotrop. 1(1/2): http:/ /www.biotaneotropica.org.br/v1n $12 / \mathrm{pt} /$ fullpaper?bn00201122001+pt (último acesso em 4/5/2006)

CONSERVATION INTERNATIONAL (CI) \& INSTITUTO DE ESTUDOS SÓCIO-AMBIENTAIS DO SUL DABAHIA (IESB). 2003. Designing sustainable landscapes. Washington, D.C.

CRANDALL, K.A., BININDA-EMONDS, O.R.P., MACE, G.M. \& WAYNE, R.K. 2000. Considering evolutionary processes in conservation biology. Trends Ecol. \& Evol. 15:290-5.

CSUTI, B., POLASKY, S., WILLIAMS, P.H., PRESSEY, R.L., CAMM, J.D., KERSHAW, M., KIESTER, A.R., DOWNS, B., HAMILTON, R., HUSO, M. \& SAHR, K. 1997. Acomparison of reserve selection algorithms using data on terrestrial vertebrates in Oregon. Biol. Cons. 80:83-97.

DALE JONES, E.B., HELFMAN, G.S., HARPER, J.O. \& BOLSTAD, P.V. 1999. Effects of riparian forest removal on fish assemblages in southern Appalachian streams. Cons. Biol. 13:1454-65.

DALE, V.H. \& BEYELER, S.C. 2001. Challenges in the development and use of ecological indicators. Ecol. Indicators 1:3-10.

DIEGUES, A.C. 1996. O mito moderno da Natureza intocada. Hucitec, São Paulo.

DOBSON, A.P., BRADSHAW, A.D. \& BAKER, A.J.M. 1997. Hopes for the future: restoration ecology and conservation biology. Science 277:515-22.
DURIGAN, G., SIQUEIRA, M.F., FRANCO, G.A.D.C. \& RATTER, J.A. 2006. Seleção de fragmentos prioritários para a criação de Unidades de Conservação do Cerrado no Estado de São Paulo. Rev. Inst. Florest. 29(2): no prelo.

FORBES, S.A. \& RICHARDSON, R.E. 1919. Some recent changes in Illinois River biology. Bul. Ill. Nat. Hist. Survey 13:139-56.

FORMAN, R.T.T. 1995. Land mosaics: the ecology of landscapes and regions. Cambridge University Press, Cambridge.

FREITAG, S., NICHOLLS, A.O. \& VAN JAARSVELD, A.S. 1996. Nature reserve selection in the Transvaal, South Africa: what data should we be using? Biodiv. Conserv. 5:685-98.

GANASAN, V. \& HUGHES, R.M. 1998. Application of an index of biological integrity (IBI) to fish assemblages of the rivers Khan and Kshipra (Madhya Pradesh), India. Fresh. Biol. 40:367-83.

GASTON, K.J. \& RODRIGUES, A.S.L. 2003. Reserve selection in regions with poor biological data. Cons. Biol. 17:188-95.

GASTON, K.J., RODRIGUES, A.S.L., VAN RENSBURG, B.J., KOLEFF, P. \& CHOWN, S.L. 2001. Complementary representation and zones of ecological transition. Ecol. Let. 4:4-9.

GASTON, K.J., PRESSEY, R.L. \& MARGULES, C.R. 2002. Persistence and vulnerability: retaining biodiversity in the landscape and in protected areas. J. Biosc. 27:361-84.

GREGORY, S.V., SWANSON, F.J., MCKEE, W.A. \& CUMMINS, K.W. 1991. An ecosystem perspective of riparian zones. BioScience 41:540-51.

GROVES, C.R., JENSEN, D.B., VALUTIS, L.L., REDFORD, K.H., SHAFFER, M.L., SCOTT, J.M., BAUMGARTNER, J.V.,HIGGINS, J.V.,BECK, M.W.\&ANDERSON, M.G. 2002. Planning for biodiversity conservation: Putting conservation science into practice. Bioscience 52:499-512.

GUTZWILLER, K.J. 2002. Applying landscape ecology in biological conservation. Springer-Verlag, Washington.

HAILA, Y. 2002. A conceptual genealogy of fragmentation research: From island biogeography to landscape ecology. Ecol. Appl. 12:321-34.

HALL, L.W., MORGAN, R.P., PERRY, E.S. \& WALTZ, A. 1999. Development of a provisional physical habitat index for Maryland freshwater streams. Maryland Department of Natural Resources, Monitoring and Non-tidal Assessment Division, Annapolis.

HANSEN,A.J., NEILSON, R.R., DALE, V.H., FLATHER, C.H., IVERSON, L.R., CURRIE, D.J., SHAFER, S., COOK, R. \& BARTLEIN, P.J. 2001. Global change in forests: Responses of species, communities, and biomes. Bioscience 51:765-79. 
HANSKI, I. 1999. Metapopulation ecology. Oxford University Press, Oxford.

HANSKI, I.A. \& GILPIN, M.E. 1997. Metapopulation biology: ecology, genetics, and evolution. Academic Press, San Diego-London.

HILL, B.H., HERLIHY, A.T., KAUFFMANN, P.R., STEVERSON, R.J., MCCORMICK, F.H. \& JOHNSON, C.B. 2000. Use of peryphyton assemblage data as an index of biotic integrity. J. N. Am. Benthol. Soc. 19:50-67.

HOWARD, P.C., VISKANIC, P., DAVENPORT, T.R.B., KIGENYI, F.W., BALTZER, M., DICKINSON, C.J., LWANGA, J.S., MATTHEWS, R.A. \& BALMFORD, A. 1998. Complementarity and the use of indicator groups for reserve selection in Uganda. Nature 394:472-5.

HUGHES, R.M. 1995. Defining acceptable biological status by comparing with reference conditions. In Biological assessment and criteria: tools for water resource planning and decision making (W.S. Davis \& T. P. Simon, eds). CRC Press Inc., Florida, p.31-47.

JAMESON, S.C., ERDMANN, M.V., KARR, J.R. \& POTTS, K.W. 2001. Charting a course toward diagnostic monitoring: a continuing review of coral reef attributes and a research strategy for creating coral reef indexes of biotic integrity. Bul. Mar. Sc. 69:701-44.

JENNINGS, M.D. 2000. Gap analysis: concepts, methods, and recent results. Landsc. Ecol. 15:5-20.

KAMDEM TOHAM,A. \& TEUGELS, G.G. 1999. First data of an Index if Biotic Integrity (IBI) based on fish assemblage for the assessment of the impact of deforestation in a tropical Wets African river system. Hydrobiol. 397:29-38.

KARR, J.R. 1981. Assessment of biotic integrity using fish communities. Fisheries 6:21-27.

KARR, J.R. \& CHU, E.W. 1999. Restoring life in running waters. Island Press, Washington D. C.

KARR, J.R. \& DIONNE, M. 1991. Designing surveys to assess biological integrity in lakes and reservoirs. In Biological criteria: research and regulation. U.S. Environmental Protection Agency, Washington D.C., EPA - 440/ 5-91-005, p.62-72.

KARR, J.R., HEIDINGER, R.C. \& HELMER, E.H. 1985. Sensitivity of the index of biotic integrity to changes in chlorine and ammonia levels from wastewater treatment facilities. J. Water Poll. Control 57:912-15.

KARR, J.R., FAUSCH, K.D., ANGERMEIER, P.L., YANT, P.R. \& SCHLOSSER, I.J. 1986. Assessing biological integrity in running waters, a method and its rationale. Nat. Hist. Surv., Special Publication 5, Urbana, USA.

KIMBERLING, D.N., KARR, J.R. \& FORE, L.S. 2001. Measuring human disturbance using terrestrial invertebrates in the shrub-steppe of eastern Washington (USA). Ecol. Indicators 1:63-81.
LEVINS, R. 1970. Extinction. In Lectures on Mathematical in Life Sciences. American Mathematical Society, Providence, Rhode Island, p.77-107.

LINDENMAYER, D.B., CUNNINGHAM, R.B., DONNELLY, C.F. \& LESSLIE, R. 2002. On the use of landscape surrogates as ecological indicators in fragmented forests. Forest Ecol. 159:203-16.

LYONS, J., NAVARRO-PEREZ, S., COCHRAN, P.A., SANTANA, E. \& GUZMÁN-ARROYO, M. 1995. Index of biotic integrity based on fish assemblages for the conservation of streams and rivers in West-Central México. Conserv. Biol. 9:569-84.

MARGULES, C.R. \& PRESSEY, R.L. 2000. Systematic conservation planning. Nature 405:243-53.

MARGULES, C.R., PRESSEY, R.L. \& WILLIAMS, P.H. 2002. Representing biodiversity: data and procedures for identifying priority areas for conservation. J. Biosc. 27:309-26.

MCCORMICK, F.H., HUGHES, R.M., KAUFFMANN, P.R., PECK, D.V., STODDARD, J.L. \& HERLIHY, A.T. 2001. Development of an index of biotic integrity for the MidAtlantic highlands region. Trans. Am. Fish. Soc. 130:857-77.

MCKENZIE, N.L., BELBIN, L., MARGULES, C.R. \& KEIGHERY, G.J. 1989. Selecting representative reserve systems in remote areas - a case study in the Nullarbor region, Australia. Biol. Cons. 50:239-61.

METZGER, J.P. 2001. O que é ecologia de paisagens? Biota Neotrop. 1(1/2): http://www.biotaneotropica.org.br/ v1n12/pt/fullpaper?bn00701122001+pt (ultimo acesso em 04/05/2006).

MICACCHION, M. 2002. Amphibian index of biotic integrity (AmphIBI) for wetlands. Final Report EPA Grant nCD985875-01, Ohio.

MILLER, D.L., LEONARD, P.M., HUGHES, R.M., KARR, J.R., MOYLE, P.B., SCHRADER, L.H., THOMPSON, B.A., DANIELS, R.A., FAUSCH, K.D., FITZHUGH, G.A., GAMMON, J.R., HALLIWELL, D.B., ANGERMEIER, P.L. \& ORTH, D.J. 1988. Regional applications of an index of biotic integrity for use in water resource mamagement. Fisheries 13:12-20.

NOSS, R.F. 1990. Indicators for monitoring biodiversity - a hierarchical approach. Cons. Biol. 4:355-64.

OBERDORFF, T. \& HUGHES, R.M. 1992. Modification of an Index of Biotic Integrity based on fish assemblages to characterize rivers of the Seine Basin, France. Hydrobiol. 228:117-30.

PECK, S. 1998. Planning for biodiversity: issues and examples. Island Press, Washington.

PRESSEY, R.L. \& NICHOLLS, A.O. 1989a. Application of a numerical algorithm to the selection of reserves in SemiArid New-South-Wales. Biol. Cons. 50:263-78. 
PRESSEY, R.L. \& NICHOLLS, A.O. 1989b. Efficiency in conservation evaluation - scoring versus iterative approaches. Biol. Cons. 50:199-218.

PRESSEY, R.L., HUMPHRIES, C.J., MARGULES, C.R., VANEWRIGHT, R.I. \& WILLIAMS, P.H. 1993. Beyond opportunism - key principles for systematic reserve selection. Trends Ecol. Evol. 8:124-8.

PRESSEY, R.L., POSSINGHAM, H.P. \& MARGULES, C.R. 1996. Optimality in reserve selection algorithms: when does it matter and how much? Biol. Cons. 76:259-67.

REDFORD, K.H. \& RICHTER, B.D. 1999. Conservation of biodiversity in a world of use. Cons. Biol. 13:1246-56.

REDFORD, K.H., COPPOLILLO, P., SANDERSON, E.W., DA FONSECA, G.A.B., DINERSTEIN, E., GROVES, C., MACE, G., MAGINNIS, S., MITTERMEIER, R.A., NOSS, R., OLSON, D., ROBINSON, J.G, VEDDER,A. \&WRIGHT, M. 2003. Mapping the conservation landscape. Cons. Biol. 17:116-31.

RIBEIRO, M.C.L.B. 1994. Conservação da integridade biótica das comunidades de peixes do Ribeirão Gama: Área de Proteção Ambiental (APA) Gama / Cabeça de Veado, Brasília, DF. Tese de doutorado, Universidade Estadual Paulista, Rio Claro.

RODRIGUES, A.S.L., TRATT, R., WHEELER, B.D. \& GASTON, K.J. 1999. The performance of existing networks of conservation areas in representing biodiversity. P. Roy. Soc. B 266:1453-60.

RODRIGUES, A.S., CERDEIRA, J.O. \& GASTON, K.J. 2000. Flexibility, efficiency, and accountability: adapting reserve selection algorithms to more complex conservation problems. Ecography 23:565-74.

ROTH, N.E., ALLAN, J.D. \& ERICKSON, D.L. 1996. Landscape influences on stream biotic integrity assessed at multiple spatial scales. Landsc. Ecology 11:141-56.

SAUNDERS, D.L., MEEUWIG J.J. \& VINCENT, A.C.J. 2002. Freshwater protected areas: strategies for conservation. Cons. Biol. 16:30-41.

SCOTT, J.M., DAVIS, F., CSUTI, B., NOSS, R., BUTTERFIELD, B., GROVES, C., ANDERSON, H., CAICCO, S., DERCHIA, F., EDWARDS, T.C., ULLIMAN, J. \& WRIGHT, R.G. 1993. Gap Analysis - a geographic approach to protection of biological diversity. Wild. Mon.:1-41.

SCOTT, J.M., MURRAY, M., WRIGHT, R.G., CSUTI, B., MORGAN, P. \& PRESSEY, R.L. 2001. Representation of natural vegetation in protected areas: capturing the geographic range. Biodiv. Conserv. 10:1297-301.

SHAFER, C.L. 1999. National park and reserve planning to protect biological diversity: some basic elements. Landsc. Urb. 44:123-53.
SHAFER, C.L.2001. Inter-reserve distance. Biol. Cons. 100:215-27.

SOULÉ, M.E. \& TERBORGH, J. 1999. Conserving nature at regional and continental scales - a scientific program for North America. Bioscience 49:809-17.

STEWART, T.J. 1992. A critical survey on the status of multiple criteria decision making theory and practice. OMEGA Int. J. Mgmt. Sci. 20:569-86.

STEWART, J.S., WANG, L.Z., LYONS, J., HORWATICH, J.A. \& BANNERMAN, R. 2001. Influences of watershed, riparian-corridor, and reach-scale characteristics on aquatic biota in agricultural watersheds. J. Am. Water Res. As. 37:1475-87.

STOPIGLIA, R. 2001. Diversidade e aspectos da biologia de duas comunidades de peixes do Ribeirão Bonito, bacia do Alto Rio Paraná, SP. Monografia de conclusão de curso, Faculdade de Filosofia, Ciências e Letras de Ribeirão Preto, Universidade de São Paulo, São Paulo.

STRIBLING, J.B., JESSUP, B.J., WHITE, J.S., BOWARD, D. \& HURD, M. 1998. Development of a benthic index of biotic integrity for Maryland streams. Prepared by Tetra Tech Inc. for the Maryland Department of Natural Resources, Monitoring and Non-Tidal Assessment division, Annapolis, Maryland, CBWP-EA-98-3.

WEISBERG, S.B., RANASINGHE, J.A., SCHAFFNER, L.C., DIAZ, R.J., DAUER, D.M. \& FRITHSEN, J.B. 1997. An estuarine benthic index of biotic integrity (B-IBI) for Chesapeake Bay. Estuaries 20:149-58.

WESSELS, K.J., FREITAG, S. \& VAN JAARSVELD, A.S. 1999. The use of land facets as biodiversity surrogates during reserve selection at a local scale. Biol. Cons. 89:21-38.

WIENS, J.A. 1995. Habitat fragmentation - island v landscape perspectives on bird conservation. Ibis 137:S97-S104.

Título: Do diagnóstico à conservação da biodiversidade: o estado da arte do programa BIOTA/FAPESP.

Autores: Metzger, J.P \& Casatti, L.

Biota Neotropica, Vol. 6 ( número 2 ): 2006

http://www.biotaneotropica.org.br/v6n2/pt/ abstract?point-of-view+bn00106022006

Recebido em 20/12/05 - Versão reformulada recebida em 20/04/2006 - Publicado em 01/05/2006

ISSN 1676-0603 


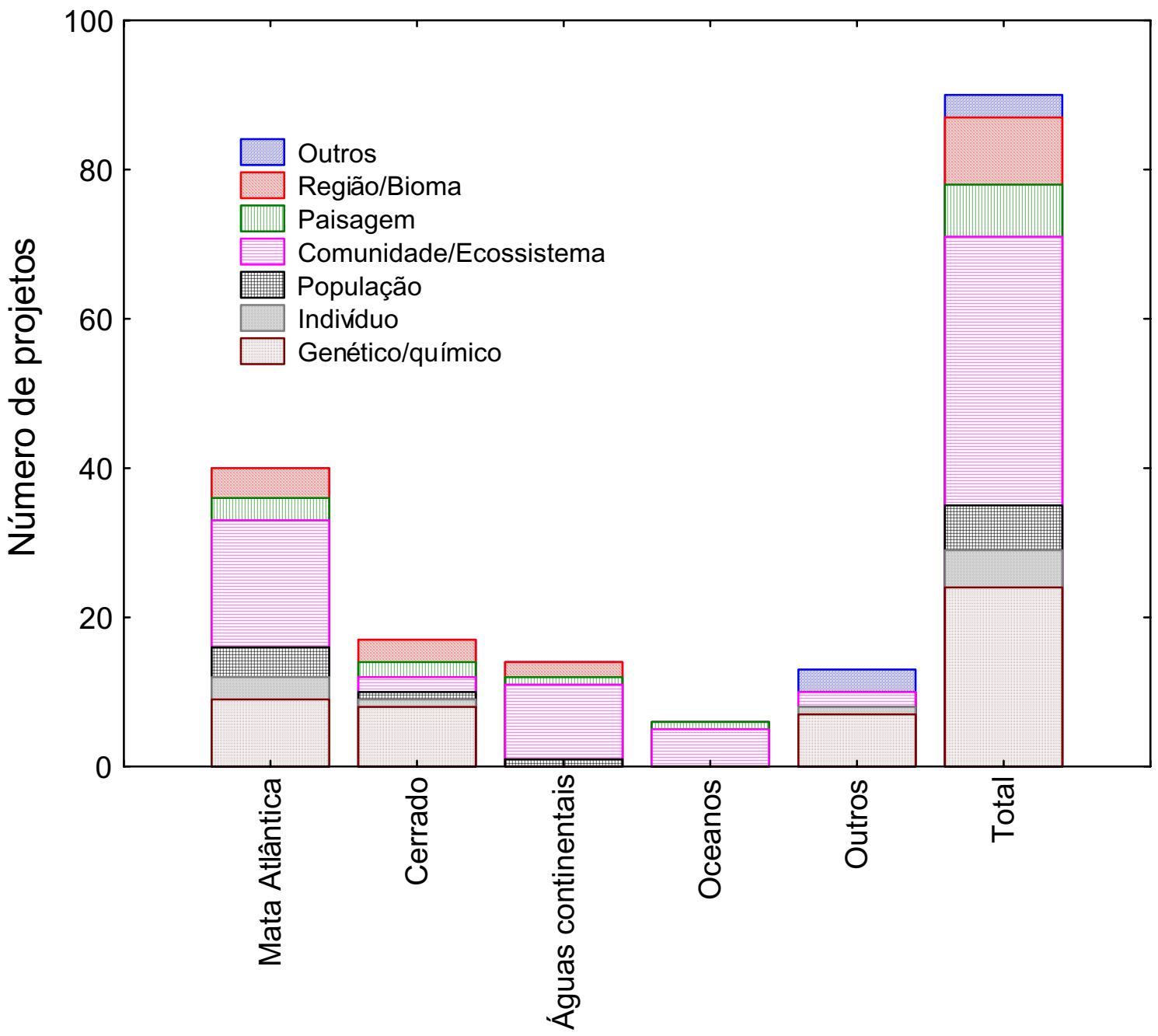

Figura 1. Níveis de organização biológica considerados pelos projetos do Programa BIOTA/FAPESP em andamento ou finalizados em dezembro de $2005(N=71)$. Como um mesmo projeto pode lidar com vários níveis, a coluna total tem $N>70$.

Figure 1. Biological levels of organization encompassed by the BIOTA/FAPESP Program projects in course or finalized until 2005December $(N=71)$. Because each unique project can deal with several levels, the total column shows $N>71$. 


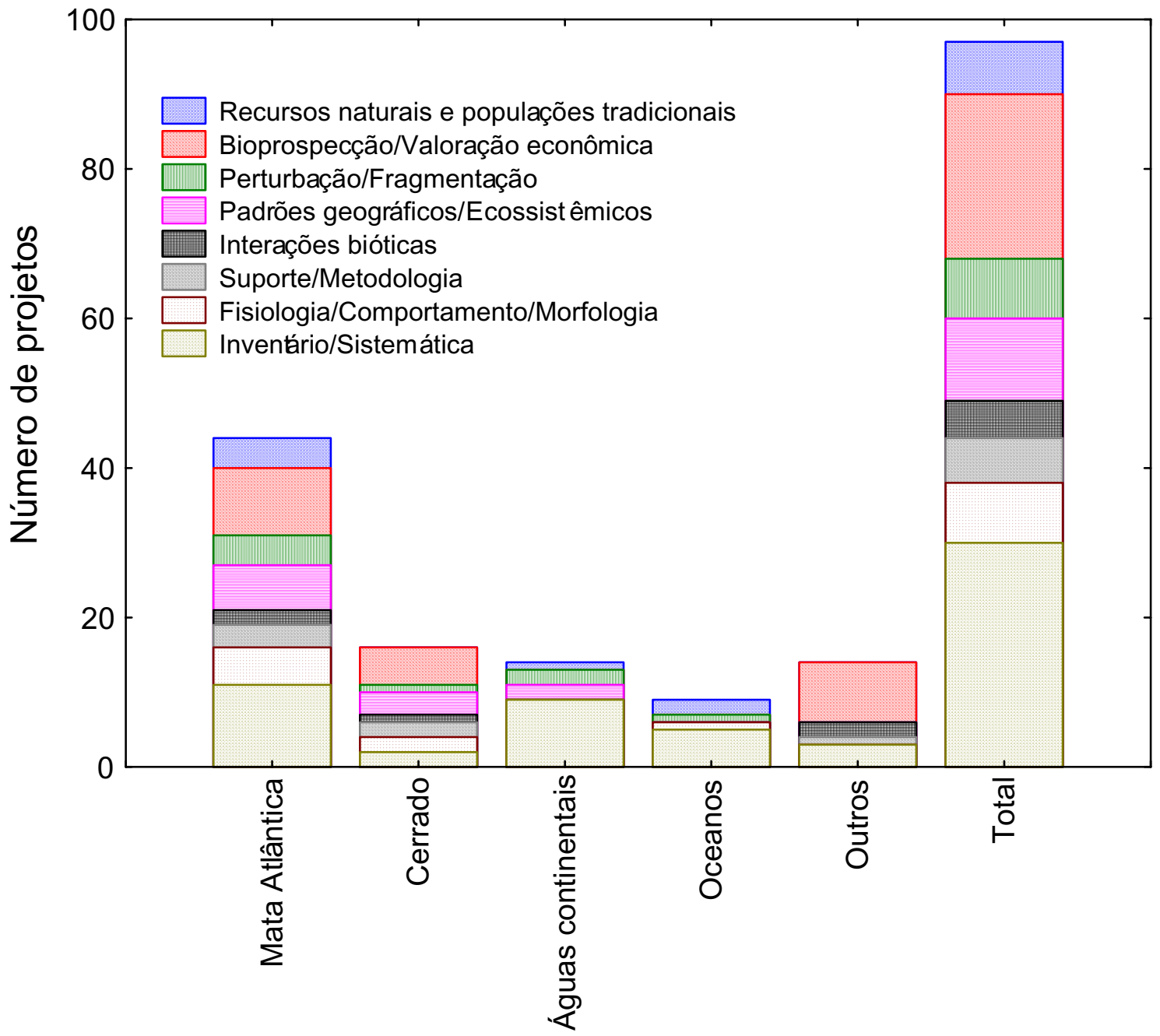

Figura 2. Objetivos principais dos projetos do Programa BIOTA/FAPESP em andamento ou finalizados em dezembro de 2005 (N = 71$)$. Como um mesmo projeto pode ter diferentes objetivos, a coluna total tem $N>70$.

Figure 2. Main objectives of the BIOTA/FAPESP Program projects in course or finalized until 2005 December $(N=71)$. Because each unique project can deal with several levels, the total column shows $N>71$. 


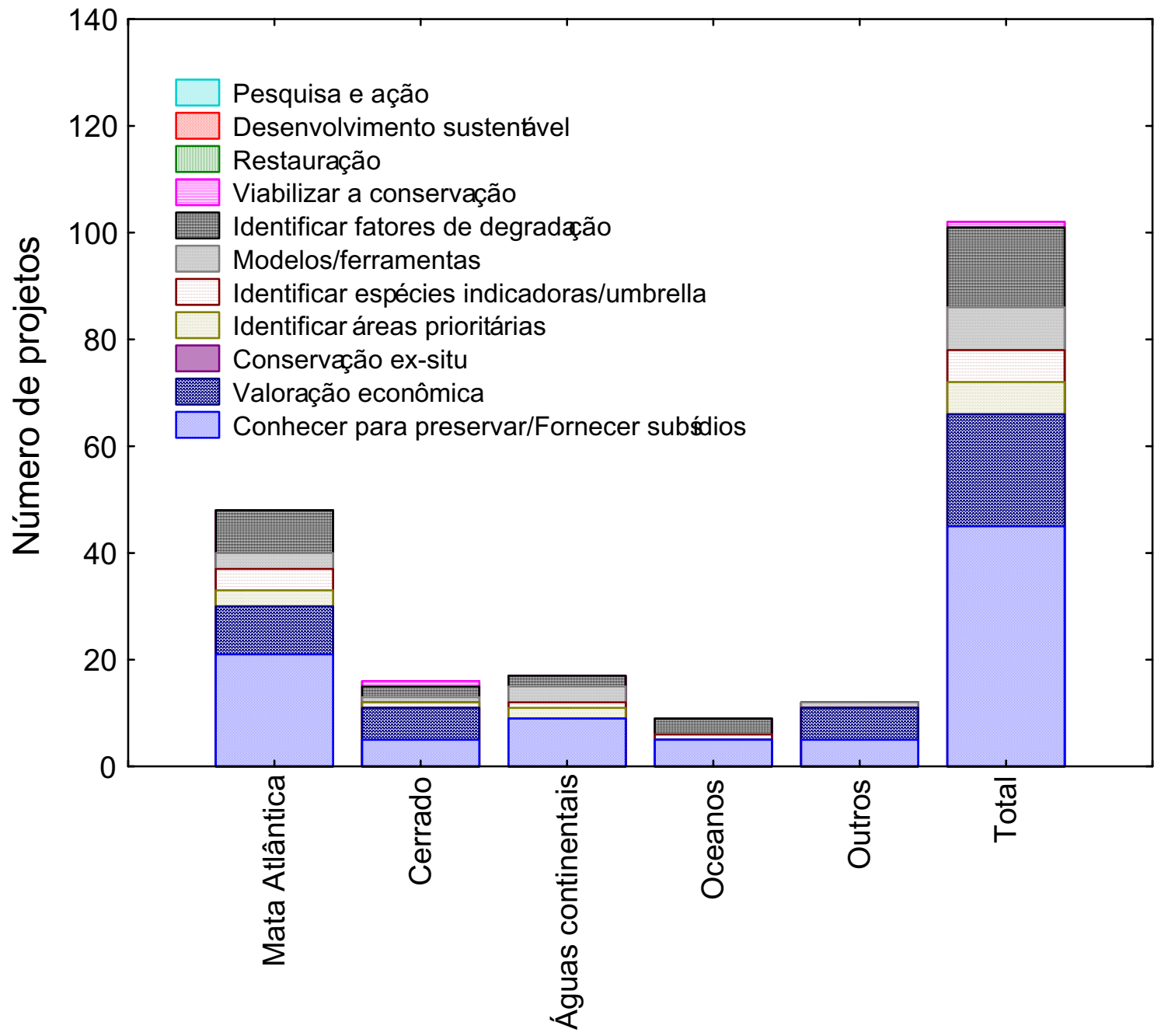

Figura 3. Principais contribuições para a conservação dos projetos do Programa BIOTA/FAPESP em andamento ou finalizados em dezembro de $2005(N=71)$. Como um mesmo projeto pode ter diferentes tipos de contribuição, a coluna total tem $N>70$.

Figure 3. Main contributions of the BIOTA/FAPESP Program projects in course or finalized up to 2005 December (N = 71) to conservation. Because each unique project can deal with several levels, the total column shows $N>71$. 


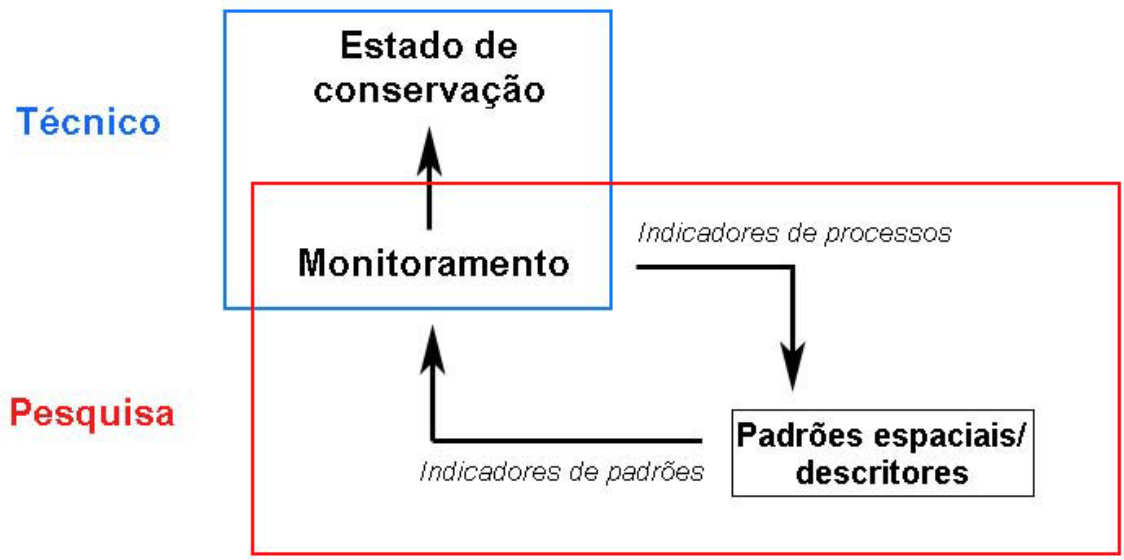

Figura 4. Monitoramento como mecanismo de desenvolvimento de indicadores ecológicos funcionais (pesquisa) e como instrumento de avaliação do estado de conservação em trabalhos técnicos.

Figure 4. Monitoring as a mechanism to the development of functional ecological indicators (research) and as an evaluation tool of the state of conservation in technical works. 


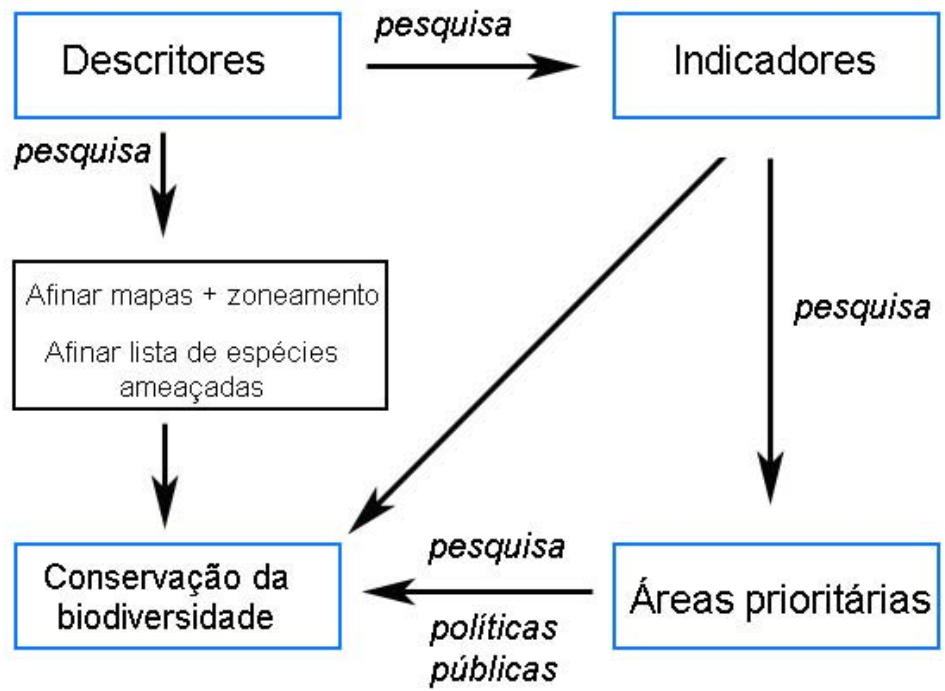

Figura 5. Síntese gráfica das propostas de ações para o uso dos inventários biológicos do Programa BIOTA/FAPESP em ações/projetos voltados para conservação.

Figure 5. Graphic synthesis of the actions proposed for use of the BIOTA/FAPESP Program biological inventories in actions/projects directed to conservation. 
Tabela 1. Componentes, padrões, processos e potenciais indicadores da condição biológica em quatro níveis de organização (Noss 1990, Peck 1998).

\begin{tabular}{|c|c|c|c|c|}
\hline & Componentes & Padrões & Processos & $\begin{array}{c}\text { Descritores } \\
\text { (Potenciais indicadores) } \\
\end{array}$ \\
\hline 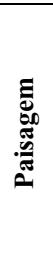 & $\begin{array}{c}\text { Tipos de comunidade e } \\
\text { características (proporção, } \\
\text { raridade, produtividade, } \\
\text { diversidade); características } \\
\text { hidrológicas, fatores abióticos } \\
\text { (e.g., clima, solos, } \\
\text { topografia...); tipo de uso do } \\
\text { solo }\end{array}$ & $\begin{array}{l}\text { Diversidade; conectividade; } \\
\text { fragmentação; tamanho, } \\
\text { forma e distribuição das } \\
\text { manchas; diversidade de } \\
\text { bordas }\end{array}$ & $\begin{array}{l}\text { Regime de perturbação em larga } \\
\text { escala (queimadas, inundações, } \\
\text { tempestades, etc.), mudança na } \\
\text { vegetação e nas características } \\
\text { hidrológicas a longo prazo; fluxo } \\
\text { de nutrientes; mudanças no } \\
\text { padrão de uso e cobertura }\end{array}$ & $\begin{array}{l}\text { Tamanho das manchas, grau de } \\
\text { agregação, conectividade }\end{array}$ \\
\hline نُ & $\begin{array}{c}\text { Tipo de espécies (raridade, } \\
\text { sensibilidade, exótica/nativa); } \\
\text { habitat chave }\end{array}$ & $\begin{array}{l}\text { Estrutura da vegetação } \\
\text { (densidade, número e grau } \\
\text { de abertura dos estratos), } \\
\text { distribuição das espécies e } \\
\text { recursos de habitat }\end{array}$ & $\begin{array}{l}\text { Perturbação em escalas mais } \\
\text { pontuais; mudanças de vegetação } \\
\text { por sucessão; produtividade; } \\
\text { herbivoria; predação e } \\
\text { parasitismo; fluxo de nutrientes; } \\
\text { uso e impactos humanos }\end{array}$ & $\begin{array}{l}\text { Riqueza de grupos sensíveis, } \\
\text { grau de endemismo, raridade, } \\
\text { especialização }\end{array}$ \\
\hline 胥 & Tamanho absoluto e relativo & $\begin{array}{l}\text { Número e distribuição das } \\
\text { populações; distância entre } \\
\text { populações; padrões de } \\
\text { migração; estrutura } \\
\text { populacional }\end{array}$ & $\begin{array}{l}\text { Reprodução, mortalidade; } \\
\text { regeneração; capacidade de } \\
\text { deslocamento; dinâmica de } \\
\text { metapopulação }\end{array}$ & $\begin{array}{c}\text { Presença/abundância de espécies } \\
\text { sensíveis ou guarda-chuva, } \\
\text { modelos de viabilidade } \\
\text { populacional ou } \\
\text { metapopulacional }\end{array}$ \\
\hline : & Variedade de genes & $\begin{array}{c}\text { Diversidades em um } \\
\text { indivíduo; variações entre } \\
\text { populações }\end{array}$ & $\begin{array}{c}\text { Taxa de mutação, recombinação, } \\
\text { seleção }\end{array}$ & $\begin{array}{l}\text { Variabilidade genética, número } \\
\text { de alelos, grau de especificidade } \\
\text { genética }\end{array}$ \\
\hline
\end{tabular}


Anexo 1. Lista de projetos utilizados no diagnóstico do Programa BIOTA/FAPESP (projetos em andamento ou finalizados até dezembro de 2005). Os projetos estão ordenados pelo nome do coordenador.

\begin{tabular}{|c|c|c|c|}
\hline & Projeto & Coordenador & Instituição sede \\
\hline 1 & $\begin{array}{l}\text { Etnoecologia do mar e da terra na costa paulista da } \\
\text { Mata Atlântica: áreas de pesca e uso de recursos } \\
\text { naturais }\end{array}$ & Alpina Begossi & NEPAM/Unicamp \\
\hline 2 & $\begin{array}{l}\text { Monitoramento e ampliação do banco de } \\
\text { germoplasma de plantas medicinais do Cerrado }\end{array}$ & $\begin{array}{l}\text { Ana Maria Soares } \\
\text { Pereira }\end{array}$ & $\begin{array}{l}\text { Universidade de } \\
\text { Ribeirão Preto }\end{array}$ \\
\hline 3 & $\begin{array}{l}\text { Biodiversidade bêntica marinha no estado de São } \\
\text { Paulo }\end{array}$ & $\begin{array}{l}\text { Antonia Cecília } \\
\text { Zacagnini Amaral }\end{array}$ & IB/UNICAMP \\
\hline 4 & $\begin{array}{l}\text { Biodiversidade de Arachnida e Myriapoda no Estado } \\
\text { de São Paulo }\end{array}$ & $\begin{array}{l}\text { Antonio Domingos } \\
\text { Brescovit }\end{array}$ & $\begin{array}{l}\text { Instituto Butantan, } \\
\text { Secretaria de Estado } \\
\text { da Saúde }\end{array}$ \\
\hline 5 & $\begin{array}{l}\text { Desenvolvimento e estruturação de um Sistema de } \\
\text { Informação Ambiental para o Programa Biota/Fapesp }\end{array}$ & Carlos Alfredo Joly & $\begin{array}{l}\text { IB/UNICAMP \& } \\
\text { CRIA }\end{array}$ \\
\hline 6 & Ecofisiologia de plantas neotropicais & Carlos Alfredo Joly & IB/UNICAMP \\
\hline 7 & $\begin{array}{l}\text { Sistema de Informação Ambiental do Programa } \\
\text { Biota/Fapesp - Desenvolvimento de indicadores para } \\
\text { monitoramento, atualização da legenda da base } \\
\text { cartográfica e aperfeiçoamento da revista Biota } \\
\text { Neotropica }\end{array}$ & Carlos Alfredo Joly & $\begin{array}{l}\text { IB/UNICAMP \& } \\
\text { CRIA }\end{array}$ \\
\hline 8 & $\begin{array}{l}\text { Gradiente Funcional - Composição florística, } \\
\text { estrutura e funcionamento da Floresta Ombrófila } \\
\text { Densa dos núcleos Picinguaba e Santa Virgínia do } \\
\text { Parque Estadual da Serra do Mar, São Paulo, Brasil. }\end{array}$ & Carlos Alfredo Joly & IB/UNICAMP \\
\hline 9 & Flora ficológica do Estado de São Paulo & $\begin{array}{l}\text { Carlos Eduardo } \\
\text { Bicudo }\end{array}$ & $\begin{array}{c}\text { Instituto de } \\
\text { Botânica, Secretaria } \\
\text { de Estado do Meio } \\
\text { Ambiente }\end{array}$ \\
\hline 10 & Biodiversidade de Isoptera e Hymenoptera & $\begin{array}{l}\text { Carlos Roberto F. } \\
\text { Brandão }\end{array}$ & $\begin{array}{c}\text { Museu de } \\
\text { Zoologia/USP }\end{array}$ \\
\hline 11 & $\begin{array}{l}\text { Diversidade de anfíbios anuros do Estado de São } \\
\text { Paulo }\end{array}$ & $\begin{array}{l}\text { Célio Fernando } \\
\text { Baptista Haddad }\end{array}$ & $\begin{array}{l}\text { IB/UNESP Rio } \\
\text { Claro }\end{array}$ \\
\hline 12 & $\begin{array}{l}\text { Levantamento e biologia de crustáceos, insetos e } \\
\text { moluscos de água doce do Estado de São Paulo }\end{array}$ & $\begin{array}{l}\text { Claudio G. } \\
\text { Froehlich }\end{array}$ & $\begin{array}{l}\text { FFCL/USP Ribeirão } \\
\text { Preto }\end{array}$ \\
\hline 13 & $\begin{array}{l}\text { Levantamento e biologia de Insecta e Oligochaeta } \\
\text { aquáticos de sistemas lóticos do Estado de São Paulo }\end{array}$ & $\begin{array}{l}\text { Claudio G. } \\
\text { Froehlich }\end{array}$ & $\begin{array}{l}\text { FFCL/USP Ribeirão } \\
\text { Preto }\end{array}$ \\
\hline 14 & $\begin{array}{l}\text { Limites geográficos e fatores causais de endemismo } \\
\text { na Floresta Atlântica em Diptera }\end{array}$ & $\begin{array}{l}\text { Dalton de Souza } \\
\text { Amorim }\end{array}$ & $\begin{array}{l}\text { FFCL/USP Ribeirão } \\
\text { Preto }\end{array}$ \\
\hline 15 & $\begin{array}{l}\text { Diversidade e conservação da fauna de répteis do } \\
\text { sudeste da Floresta Atlântica }\end{array}$ & $\begin{array}{c}\text { Denise M. } \\
\text { Peccinini-Seale }\end{array}$ & $\mathrm{IB} / \mathrm{USP}$ \\
\hline 16 & $\begin{array}{l}\text { BIOprospecTA - Search for potential antitumoral, } \\
\text { antioxidant, antiinflamatory, antidiabetic, } \\
\text { acetylcholinesterase and mieloperoxidase inhibitory } \\
\text { natural compounds from Cerrado and Atlantic Forest }\end{array}$ & $\begin{array}{l}\text { Dulce Helena } \\
\text { Siqueira Silva }\end{array}$ & $\begin{array}{l}\text { IB/UNESP Rio } \\
\text { Claro }\end{array}$ \\
\hline 17 & $\begin{array}{l}\text { Coleta, uso e caracterização da diversidade genética } \\
\text { de germoplasma de batata-doce (Ipomoea batatas L. } \\
\text { Lam.) e cará (Dioscorea spp.) em roças de agricultura } \\
\text { tradicional do Vale do Ribeira, SP, Brasil }\end{array}$ & $\begin{array}{l}\text { Elizabeth Ann } \\
\text { Veasey }\end{array}$ & $\begin{array}{l}\text { ESALQ/USP } \\
\text { Piracicaba }\end{array}$ \\
\hline 18 & $\begin{array}{l}\text { Biodiversidade vegetal e de organismos edáficos em } \\
\text { ecossistemas de Araucaria angustifolia naturais e } \\
\text { impactados no Estado de São Paulo }\end{array}$ & $\begin{array}{l}\text { Elke J. B. N. } \\
\text { Cardoso }\end{array}$ & $\begin{array}{l}\text { ESALQ/USP } \\
\text { Piracicaba }\end{array}$ \\
\hline 19 & $\begin{array}{l}\text { Estudos de embriogênese como subsídios para } \\
\text { estratégias de reprodução e conservação de espécies } \\
\text { arbóreas }\end{array}$ & $\begin{array}{l}\text { Eny Iochevet Segal } \\
\text { Floh }\end{array}$ & IB/USP \\
\hline 20 & $\begin{array}{l}\text { Sistemática, revisão taxonômica e biogeografia da } \\
\text { tribo Heptapterini Gill, } 1861 \text { (Ostariophysi, } \\
\text { Siluriformes, Heptapteridae) }\end{array}$ & $\begin{array}{l}\text { Flávio A. } \\
\text { Bockmann }\end{array}$ & $\begin{array}{l}\text { FFCL/USP Ribeirão } \\
\text { Preto }\end{array}$ \\
\hline 21 & $\begin{array}{l}\text { Levantamento fisionômico das comunidades } \\
\text { bentônicas de substrato consolidado do litoral }\end{array}$ & $\begin{array}{l}\text { Flávio A. S. } \\
\text { Berchez }\end{array}$ & IB/USP \\
\hline
\end{tabular}




\begin{tabular}{|c|c|c|c|}
\hline 22 & A ictiofauna da região do Alto rio Paraná & Francisco Langeani & $\begin{array}{l}\text { IBILCE/UNESP } \\
\text { São José do Rio } \\
\text { Preto }\end{array}$ \\
\hline 23 & $\begin{array}{l}\text { Consolidação da informatização da coleção de peixes } \\
\text { do Departamento de Zoologia (DZSJRP) IBILCE/ } \\
\text { UNESP, São José do Rio Preto, SP }\end{array}$ & Francisco Langeani & $\begin{array}{l}\text { IBILCE/UNESP } \\
\text { São José do Rio } \\
\text { Preto }\end{array}$ \\
\hline 24 & $\begin{array}{l}\text { Estudo ambiental no estuário do Rio Itanhaém, litoral } \\
\text { sul do Estado de São Paulo }\end{array}$ & $\begin{array}{l}\text { Fresia Ricardi- } \\
\text { Branco }\end{array}$ & IGE/UNICAMP \\
\hline 25 & $\begin{array}{l}\text { Diversidade de ácaros de importância agrícola e } \\
\text { outros artrópodos a eles associados no estado de São } \\
\text { Paulo }\end{array}$ & $\begin{array}{l}\text { Gilberto J. de } \\
\text { Moraes }\end{array}$ & $\begin{array}{l}\text { ESALQ/USP } \\
\text { Piracicaba }\end{array}$ \\
\hline 26 & $\begin{array}{l}\text { Ecologia molecular e taxonomia polifásica de } \\
\text { bactérias de importância ambiental e agroindustrial }\end{array}$ & $\begin{array}{l}\text { Gilson Paulo } \\
\text { Manfio }\end{array}$ & $\begin{array}{l}\text { CCT/Fundação } \\
\text { "André Tosello" }\end{array}$ \\
\hline 27 & $\begin{array}{l}\text { Atlas Ambiental do município de São Paulo. Fase 1: } \\
\text { diagnósticos e bases para a definição de políticas } \\
\text { públicas para as áreas verdes de São Paulo }\end{array}$ & Harmi Takiya & $\begin{array}{l}\text { Secretaria do Verde, } \\
\text { Prefeitura } \\
\text { Municipal de São } \\
\text { Paulo }\end{array}$ \\
\hline 28 & $\begin{array}{l}\text { Métodos de inventário da biodiversidade de espécies } \\
\text { arbóreas }\end{array}$ & $\begin{array}{l}\text { Hilton Thadeu } \\
\text { Zarate do Couto }\end{array}$ & $\begin{array}{l}\text { ESALQ/USP } \\
\text { Piracicaba }\end{array}$ \\
\hline 29 & $\begin{array}{l}\text { Interação biosfera-atmosfera em ecossistemas naturais } \\
\text { e agroecossistemas: um monitoramento sobre cana- } \\
\text { de-açúcar e Cerrado }\end{array}$ & $\begin{array}{l}\text { Humberto Ribeiro } \\
\text { da Rocha }\end{array}$ & IAG/USP \\
\hline 30 & $\begin{array}{l}\text { Evolução da fauna de répteis no Sudeste brasileiro do } \\
\text { Cretáceo superior ao recente: paleontologia, filogenia } \\
\text { e biogeografia }\end{array}$ & $\begin{array}{l}\text { Hussam El Dine } \\
\text { Zaher }\end{array}$ & $\begin{array}{c}\text { Museu de } \\
\text { Zoologia/USP }\end{array}$ \\
\hline 31 & $\begin{array}{l}\text { Diversidade de microrganismos endofíticos e seu } \\
\text { potencial biotecnológico }\end{array}$ & $\begin{array}{l}\text { Itamar Soares de } \\
\text { Melo }\end{array}$ & EMBRAPA \\
\hline 32 & $\begin{array}{l}\text { BIOprospecTA - Bioprospection in fungi: the search } \\
\text { of lead compouds for drug design and enzymes for } \\
\text { pharmaceutical and industrial applications }\end{array}$ & $\begin{array}{l}\text { Jairo Kenupp } \\
\text { Bastos }\end{array}$ & $\begin{array}{l}\text { FCFRP/USP } \\
\text { Ribeirão Preto }\end{array}$ \\
\hline 33 & $\begin{array}{l}\text { Conservação da biodiversidade em paisagens } \\
\text { fragmentadas do Planalto Atlântico do Estado de São } \\
\text { Paulo }\end{array}$ & Jean Paul Metzger & IB/USP \\
\hline 34 & $\begin{array}{l}\text { Unidades fisionômico-ecológicas associadas aos } \\
\text { remanescentes da cobertura vegetal natural }\end{array}$ & $\begin{array}{l}\text { João Batista } \\
\text { Baitello }\end{array}$ & $\begin{array}{l}\text { Instituto Florestal, } \\
\text { Secretaria de Estado } \\
\text { do meio Ambiente }\end{array}$ \\
\hline 35 & $\begin{array}{l}\text { BIOprospecTA - Anti-bacterial and anti-cancer } \\
\text { activity of crude extracts and active compounds } \\
\text { obtained from plants and microorganisms }\end{array}$ & $\begin{array}{l}\text { João Ernesto de } \\
\text { Carvalho }\end{array}$ & CPQBA/UNICAMP \\
\hline 36 & $\begin{array}{l}\text { BIOprospecTA - Bioprospection on the metabolism } \\
\text { of prokaryotes from brazilian biomas: exploitation of } \\
\text { microbial transformations for synthesis of chiral } \\
\text { pharmaceuticals and bioactive compounds }\end{array}$ & $\begin{array}{l}\text { João Valdir } \\
\text { Comasseto }\end{array}$ & IQ/USP \\
\hline 37 & $\begin{array}{l}\text { Lepidoptera do Estado de São Paulo: diversidade, } \\
\text { distribuição e recursos }\end{array}$ & Keith S. Brown Jr. & $\begin{array}{l}\text { Museu de História } \\
\text { Natural/UNICAMP }\end{array}$ \\
\hline 38 & $\begin{array}{l}\text { Avaliação da integridade biótica dos riachos da região } \\
\text { noroeste do Estado de São Paulo, bacia do Alto } \\
\text { Paraná, utilizando comunidades de peixes }\end{array}$ & Lilian Casatti & $\begin{array}{l}\text { IBILCE/UNESP } \\
\text { São José do Rio } \\
\text { Preto }\end{array}$ \\
\hline 39 & $\begin{array}{l}\text { Estudos etnobotânicos qualitativos e quantitativos em } \\
\text { comunidades tradicionais no PETAR, Iporanga, SP }\end{array}$ & Lin Chau Ming & $\begin{array}{l}\text { FCA/UNESP } \\
\text { Botucatu }\end{array}$ \\
\hline 40 & $\begin{array}{l}\text { Distribuição e abundância de vertebrados em relação } \\
\text { à estrutura da paisagem na bacia do Rio Passa-Cinco }\end{array}$ & $\begin{array}{l}\text { Luciano M. } \\
\text { Verdade }\end{array}$ & $\begin{array}{l}\text { ESALQ/USP } \\
\text { Piracicaba }\end{array}$ \\
\hline 41 & $\begin{array}{l}\text { BIOprospecTA - Busca de inibidores de proteínas } \\
\text { antioxidantes de Xylella fastidiosa }\end{array}$ & $\begin{array}{l}\text { Luis Eduardo } \\
\text { Soares Netto }\end{array}$ & IB/USP \\
\hline 42 & $\begin{array}{l}\text { Estrutura e funcionamento de bacias hidrográficas de } \\
\text { meso e micro escala do Estado de São Paulo: bases } \\
\text { para gerar e sustentar a biodiversidade }\end{array}$ & $\begin{array}{l}\text { Luiz Antonio } \\
\text { Martinelli }\end{array}$ & $\begin{array}{l}\text { CENA/USP } \\
\text { Piracicaba }\end{array}$ \\
\hline
\end{tabular}


43 Caracterização florística e estrutural de onze fragmentos de Mata Estacional Semidecidual da APA de Souzas e Joaquim Egídio, Campinas, SP

44 Estudos morfológicos, anatômicos, histoquímicos e ultra-estruturais em plantas do Cerrado senso lato do estado de São Paulo

45 Conservação e utilização sustentável da biodiversidade vegetal do Cerrado e Mata Atlântica: os carboidratos de reserva e seu papel no estabelecimento e manutenção das plantas em seu ambiente natural

46 Biodiversidade de modelos reprodutivos caracterizados em espécies a serem preservadas no Estado de São Paulo

47 Florações de microalgas potencialmente nocivas do litoral do Estado de São Paulo

48 Estrutura genética de populações naturais de Cryptocarya spp. (Lauraceae) através de marcadores isoenzimáticos e de DNA

49 BIOprospecTA - Bioprospecção dentre compostos de origem natural de inibidores específicos do proteassoma 20S seguida da determinação de atividade pró-apoptótica e anti-tumoral em cultura de células tumorais

50 BIOprospecTA - Screening for specific proteasome inhibitors followed by the determination of proapoptotic and antitumoral properties in cell culture

51 Sistemática, evolução e conservação de mamíferos da região leste do Brasil

52 BIOprospecTA - A bioprospecção da fauna de artrópodes do Estado de São Paulo pela procura de compostos-líderes para o desenvolvimento racional de novos fármacos e pesticidas seletivos

53 Viabilidade de conservação dos remanescentes de Cerrado do Estado de São Paulo

54 BIOprospecTA - Passifloras nativas e cultivadas do Brasil. Avaliação farmacognóstica, química e farmacológica orientada para a valorização do uso popular e desenvolvimento de medicamentos autóctones

55 Diagnóstico das populações de aves e mamíferos cinegéticos nas Unidades de Conservação da Mata Atlântica de São Paulo

56 Diversidade de peixes de riachos e cabeceiras da bacia do Rio Ribeira de Iguape no Estado de São Paulo

57 Biodiversidade e processos sociais em São Luiz do Paraitinga, SP

58 Flora aromática da Mata Atlântica no Estado de São Paulo: composição química dos óleos voláteis e análise da atividade biológica

59 Diversidade de peixes de riachos e cabeceiras da bacia do Alto Rio Paraná no estado de São Paulo, SP

60 Diversidade de Arachnida do Parque Estadual da Cantareira

61 Diversidade, dinâmica e conservação em Florestas do Estado de São Paulo: 40ha de parcelas permanentes

\begin{tabular}{|c|c|}
\hline $\begin{array}{l}\text { Luiza Sumiko } \\
\text { Kinoshita }\end{array}$ & IB/UNICAMP \\
\hline Silvia Machado & $\begin{array}{c}\text { IBB/UNESP } \\
\text { Botucatu }\end{array}$ \\
\hline $\begin{array}{l}\text { Marcos S. } \\
\text { Buckeridge }\end{array}$ & $\begin{array}{c}\text { Instituto de } \\
\text { Botânica, Secretaria } \\
\text { de Estado do Meio } \\
\text { Ambiente }\end{array}$ \\
\hline $\begin{array}{c}\text { Maria Angelica } \\
\text { Miglino }\end{array}$ & FMVZ/USP \\
\hline Maria Célia Villac & $\begin{array}{l}\text { Universidade de } \\
\text { Taubaté }\end{array}$ \\
\hline $\begin{array}{c}\text { Maria Teresa V. C. } \\
\text { Derbyshire }\end{array}$ & $\begin{array}{l}\text { CENA/USP } \\
\text { Piracicaba }\end{array}$ \\
\hline
\end{tabular}

Marilene Demasi Instituto Butantan, Secretaria de Estado

da Saúde

Marilene Demasi Instituto Butantan,

Secretaria de Estado da Saúde Museu de Zoologia/USP

IB/UNESP Rio Claro

$\begin{array}{r}\text { Mario Sergio Palma } \quad \begin{array}{r}\text { IB/UNESP } \\ \text { Claro }\end{array} \\ \hline\end{array}$
(1)

\begin{tabular}{|c|c|}
\hline $\begin{array}{c}\text { Marisa Dantas } \\
\text { Bitencourt } \\
\text { Massayoshi } \\
\text { Yoshida }\end{array}$ & IB/USP \\
\hline Mauro Galetti & IB/UNESP Rio \\
& Claro \\
\hline $\begin{array}{c}\text { Osvaldo Takeshi } \\
\text { Oyakawa }\end{array}$ & $\begin{array}{c}\text { Museu de } \\
\text { Zoologia/USP }\end{array}$ \\
\hline $\begin{array}{c}\text { Paulo Inácio Prado } \\
\text { Paulo Roberto H. } \\
\text { Moreno }\end{array}$ & IB/USP \\
\hline $\begin{array}{c}\text { Ricardo Macedo } \\
\text { Corrêa e Castro }\end{array}$ & $\begin{array}{c}\text { FFCL/USP } \\
\text { Ricardo Pinto da } \\
\text { Rocha }\end{array}$ \\
\hline $\begin{array}{c}\text { Ricardo Ribeiro } \\
\text { Rodrigues }\end{array}$ & IB/USP \\
\hline
\end{tabular}




\begin{tabular}{|c|c|c|c|}
\hline 62 & $\begin{array}{l}\text { Distribuição da comunidade de palmeiras no } \\
\text { gradiente altitudinal da Floresta Atlântica na região } \\
\text { nordeste do estado de São Paulo }\end{array}$ & $\begin{array}{l}\text { Simey Thury Vieira } \\
\text { Fisch }\end{array}$ & $\begin{array}{l}\text { Universidade de } \\
\text { Taubaté }\end{array}$ \\
\hline 63 & $\begin{array}{l}\text { Embriologia de espécies de Asteraceae do Cerrado } \\
\text { Lato Sensu }\end{array}$ & $\begin{array}{l}\text { Simone de Pádua } \\
\text { Teixeira }\end{array}$ & $\begin{array}{l}\text { FCFRP/USP } \\
\text { Ribeirão Preto }\end{array}$ \\
\hline 64 & $\begin{array}{l}\text { Diversidade de zooplâncton em relação à conservação } \\
\text { e degradação dos ecossistemas aquáticos do estado de } \\
\text { São Paulo }\end{array}$ & Takako M. Tundisi & $\begin{array}{l}\text { Instituto } \\
\text { Internacional de } \\
\text { Ecologia de São } \\
\quad \text { Carlos }\end{array}$ \\
\hline 65 & $\begin{array}{l}\text { Diversidade de espécies e de interações em plantas e } \\
\text { insetos fitófagos }\end{array}$ & $\begin{array}{l}\text { Thomas M. } \\
\text { Lewinsohn }\end{array}$ & IB/UNICAMP \\
\hline 66 & $\begin{array}{l}\text { Conservação e utilização sustentável da } \\
\text { biodiversidade vegetal do Cerrado e Mata Atlântica: } \\
\text { diversidade química de plantas nativas de mata e } \\
\text { cerrado e seu potencial biológico }\end{array}$ & $\begin{array}{c}\text { Vanderlan da Silva } \\
\text { Bolzani }\end{array}$ & $\begin{array}{l}\text { IQ/UNESP } \\
\text { Arararaquara }\end{array}$ \\
\hline 67 & $\begin{array}{l}\text { Sistema de informação distribuído para coleções } \\
\text { biológicas: a integração do Species Analyst e } \\
\text { SinBiota }\end{array}$ & $\begin{array}{l}\text { Vanderlei Perez } \\
\text { Canhos }\end{array}$ & CRIA \\
\hline 68 & $\begin{array}{l}\text { Uso sustentável da biodiversidade brasileira: } \\
\text { prospecção químico-farmacológica em plantas } \\
\text { superiores da Mata Atlântica e do Cerrado }\end{array}$ & Wagner Vilegas & $\begin{array}{c}\text { IQ/UNESP } \\
\text { Arararaquara }\end{array}$ \\
\hline 69 & Peixes e pesca na Mata Atlântica do sul de São Paulo & Walter Barrella & PUC Sorocaba \\
\hline 70 & $\begin{array}{l}\text { Biodiversidade das interações entre vertebrados } \\
\text { frugívoros e plantas da Mata Atlântica do Sudeste do } \\
\text { Brasil }\end{array}$ & Wesley R. Silva & IB/UNICAMP \\
\hline
\end{tabular}

